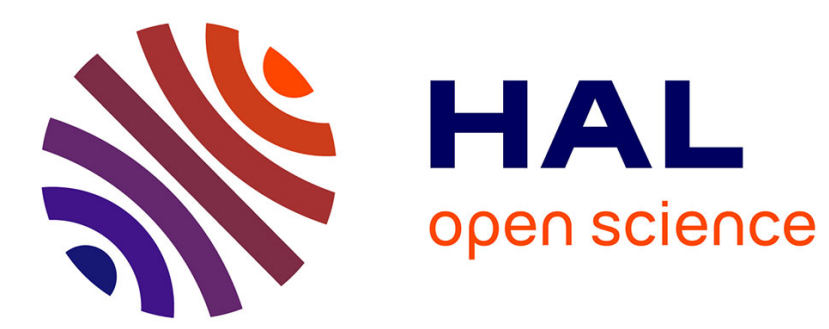

\title{
Observations sur les vases à médaillons d'applique de la vallée du Rhône
}

\author{
Hugues Vertet
}

\section{To cite this version:}

Hugues Vertet. Observations sur les vases à médaillons d'applique de la vallée du Rhône. Gallia - Fouilles et monuments archéologiques en France métropolitaine, 1969, 27 (1), pp.93-133. 10.3406/galia.1969.2520 . hal-01934106

\section{HAL Id: hal-01934106 https://hal.science/hal-01934106}

Submitted on 3 Mar 2020

HAL is a multi-disciplinary open access archive for the deposit and dissemination of scientific research documents, whether they are published or not. The documents may come from teaching and research institutions in France or abroad, or from public or private research centers.
L'archive ouverte pluridisciplinaire HAL, est destinée au dépôt et à la diffusion de documents scientifiques de niveau recherche, publiés ou non, émanant des établissements d'enseignement et de recherche français ou étrangers, des laboratoires publics ou privés.

\section{(ㅇ)(1) $\$$}

Distributed under a Creative Commons Attribution - NonCommercial - NoDerivatives| 4.0 


\title{
OBSERVATIONS SUR LES VASES A MÉDAILLONS D'APPLIQUE DE LA VALLÉE DU RHÔNE
}

\author{
par Hugues VERTET
}

Les deux ourrages principaux sur le sujet demeurent ceux de J. Déchelette et de P. Wuilleumier et A. Audin*. La première de ces études donne un répertoire de 200 fragments avec 169 types différents ${ }^{1}$; la seconde le porte à 533 pièces, avec 380 types $^{2}$. Depuis, il a été augmenté par les recherches de M. Audin, qui a publié plusicurs articles, au fur et à mesure de ses découvertes ${ }^{3}$. Le second ouvrage s'efforce aussi d'établir un classement artistique par auteur. C'est un travail difficile pour deux raisons au moins : il est fondé sur le style et la typologie, très peu de reliefs étant signés; le même thème a été traité par plusieurs auteurs. Le fait qu'on ait retrouvé des vases entiers ou presque portant plusieurs appliques n'est point une aide, car elles sont souvent d'auteurs différents ${ }^{4}$.

Sur plusieur's questions concernant notamment la fabrication et la chronologie, nous sommes très pauvres en renseignements. Il paraît utile de faire le point de nos connaissances sur ces chapitres. Elles se sont un peu augmentées depuis la parution de ces deux ouvrages magistraux.

- Joseph Dicantivtr, Les lases céramiques ornes de la Gaule romaine, 1904 t. 11, 4e partie, Vases à reliefs dapplique, serie B, vases de la vallée du Rhòne, p. 235-307 et supplément, p. 345-352 at pl. II, no 77, pl. IV, vase Sallier). Renvoi fail jci par J. I).; - P. Wull.fenter el A. Aunx, Les médaillons d'applique gallo-romains de la vallée du Rhône, 1952. Renvoi fait ici par W. A.

1 Le classement est fait par sujets : les dieux et les representations mythologiques diverses (I à XI), sujets historiques, sujets divers (XII), acteurs, représentations scéniques XIII), gladiateurs, bestiaires XIV), auriges (XV), mas(jues $X V 1)$, sujets divers et menus fragments indetermines $(\mathrm{XV} I I)$.

2 Voir à l'Annexe II la concordance des reliefs. J. Dechelette-Wuilleumier-Audin.

3 A. Atwx, lin médaillon de vase ì figure de Sucellus, dans Bull. Soc. nal. des Antiquaires de France, 1948-49, p. 169 ; - Inclum Lugudunum, dans R.A.E., juillet-sept. 1959, p. 228-229; - avec A. Br.avc et A. Dumour.ry), Medaillons d'applique de Valence el Vaison, dans Cahiers Rhodaniens, VII, 1960, p. 72-84; - In nouveau médaillon d'ap-

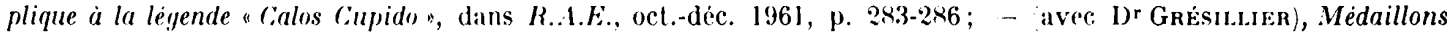
dapplique rhodaniens du Musee de Rochechouarl, dans Cahiers Rhodaniens. VIII, 1961; - Vienna Felix, dans Bul.

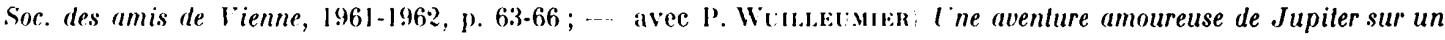
médaillon d'applique, dans Bull. Musees de Lyon, 1965, p. 269-273; -- avec W. Brssfr.s), Médaillons d'applique rhodaniens du Musee de Cologne, dans Kölner .Jarbuch für Chr- und Frühgeschichle, 1964, p. 14-18; - Le vase Chaumartin, dans Bull. Musees de Lyon, 1966, p. 343-349; -- avec H. Jeaxcol.as), Le Médaillon des amours de Mars et de Ténus, dans Bulletin des . Musées de Lyon a paraître); - avec A. Brcur.), Le médaillon de la mort d'Hector, dans Ciallia, XXVI, 196\%, p. 314-320.

1 W. A., p. 21 ; sur un vase du Musee de Cologne, les trois médaillons sont de FEI.IX vase de la collection Schallenberg, chudie par A. Audin ol WV. Binsfeld). 
Depuis Iéchelette, on situe les principaux centres de fabrication à Lyon et à Vienne (Isère) ${ }^{5}$. Voici les arguments sur lesquels on a fondé ces affirmations et quelques observations qui les confirment.

\section{LYON.}

1) Plus de 150 appliques ont été trourées dans celle ville.

2) Certains reliefs représentent la Tutelle et le Génie de Lyon.

3) Il semble que l'on puisse ajouter à ces deux faits une trouvaille du siècle dernier, ainsi rapportée par Comarmont ${ }^{6}$ : on mit au jour en 1842 «les ruines d'un four de potier, des oulils s'appliquant à la céramique, des vases de formes variées, une soixantaine de lampes, quai de serin. dans la propriété de .I. Morel, fondeur de cloches. Déjà en cet endroit, on avait fait de nombreuses découvertes, surtout de sujets érotiques". Malheureusement "la plupart de ces objets ont été brisés ou vendus à des marchands étrangers... en général, ils sont d'un bon style."

Si ces reliefs érotiques avaient appartenu à des lampes, l'auteur le mentionnerait, je pense, comme dans la deuxième trouvaille. En l'absence d'indication, c'est plutòt à des médaillons que l'on peut penser. Que l'on en ait fait un commerce n'est pas douteux. Il exista certainement au xix ${ }^{e}$ siècle un marché de ces objets. Certains aboutirent dans les réserves des llusées. Ainsi puis-je en mentionner au British . Yuseum (que je n'ai point vus sur le catalogue). Ils portent deux indirations:

a) sur une étiquette: II L suivi d'un numéro d'ordre (de 1 à 10 au moins) el au-dessous «. Mus. secr." Cette indication (Nusée secrel) indique qu'ils appartinrent un moment à un collectionneur français ;

b) une indication muséographique à l'encre de Chine : 1912/11. 25/21;1912/11. 2:/24;1912/11. 2:5/25. Si les reliefs érotiques découverts à Lyon, en 1842, sont de ce genre, l'atelier du quai de serin pourrait bien être un des centres où l'on fabriquait des vases à médaillons.

4) In quatrième argument. plus général, c'est que Lyon apparaît de plus en plus comme un centre céramique très important, et par la variété de ses fabrications et par l'influence qu'il a eu sur d'autres ateliers?. I)es analyses de terre, en cours dans les laboratoires de .I. Picon, nous donneront bientôt, je l'espère. les caractéristiques des aruiles et des mélanges employés par les artisans de la métropole des Ciaules.

\section{VIENNE.}

1) Plus de 200 appliques ont été trouvées dans cette ville.

2) Sur un médaillon, on voit apparaitre l’invoration VIFNCA FLLIX, qui cite la ville de Vienne (W. A., no 9 ).

3) Sept unoules connus sur 12 proviennent de cette ville ou de son faubourgr, siainte-Colombe (IV. A., p. 14).

5) J. 1)., p. :23x: W. A., p. 11.

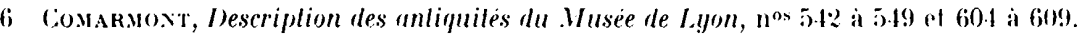

7 la decouverte d'un atelier de potiers, succursale de ceux d'llalie, en 1966, a donne lieu a plusieturs communications préliminaires, aux congres de Groupe diotude de la ceramique antipue, aux Journees de la Circonscription

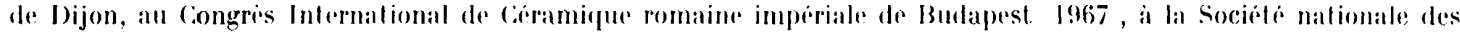

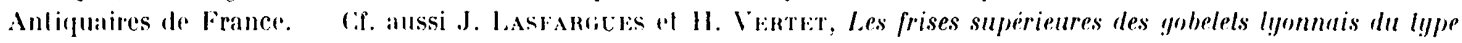

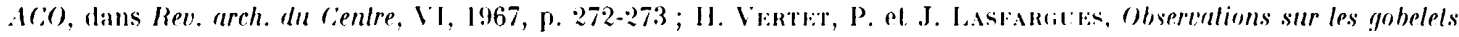

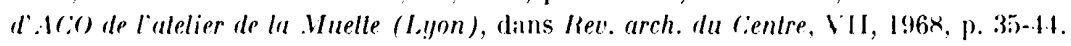


1) Outre ces arquments déja publiés, el déjà convaincants. on peul en ajouler un qualrième. Il s'agit d'une découverte mentionnée dans un manuscrit inédit. rédigé par un architecte de lloulins (Allier). Esmonnot, à la fin du sircle dernier. C'est le catalogue de sa collection particulière, qui comportait en particulier 23 moules d'applique : médaillons, grands masques. scènes diverses. "Ils ont été trouvés, écrit l'auleur. dans les travaux de déblaiement faits à Vienne pour l'établissement du Champ de Vars ${ }^{8}$. Ils ont été acquis par II. Charvet, qui me les a cédés. Je me suis informé sur les lieux de l'exactitude de la provenance. II. Girard, notaire, a èté le premier possesseur". line enquête sérieuse faite par .I. Abauzit, spécialiste de l'A tre du bronze dans l'Allier et par moimème sur d'autres indications de provenance fournies par Esmonnot dans ses publications montre que les renseignements donnés par ce collectionneur sont dignes de foi.

On pourrait s'étonner de ce que Déchelette n'ait pas mentionné cetle provenance. Il avait eu connaissance de la collection de maitre Girard. Il avait reconstitué le cheminement d'autres moules et appliques qui en avaient fait partie : cerlains de ces objets sont allés dans la collection Charvet, a Paris (par exemple J.I., no 9 a (1855), d'autres dans la collection Froehner (par exemple J.D., $\mathrm{n}^{\text {os }} 28,44,77 \mathrm{~b}$ ), d'autres au .lusée de Vienne (par exemple J.D., nos 88, 99a).

Pour ce qui est du lot de moules de la collection Esmonnot, Décheletle en signale un seul (J.I)., no 48), comme "trouvé à Vienne, ancienne collection Esmonnot, aujourd'hui Musée de St-Germain-en-Laye». Pour les autres, il écrit : "Le. Nusée de saint-Germain possède (même) une quinzaine de moules qui passent pour avoir été lrouvés à Vienne. Mais les circonstances de cette découverte n'ont été relatées nulle part. Il est mème assez étrange que les archéologues et épigraphistes viennois, II. Allmer notamment, ne l'aient jamais signalée" (J.D., p. 238). Il nous faut admettre que J. Déchelette n'a pas eu connaissance du catalogue Esmonnot, car, même s'il avail contesté l'origine viennoise, ce qu'il ne semble pas faire, il aurait mentionné le passage de ces objets dans la collection moulinoise. Chaque fois qu'il le peut, en effet, il cite les propriétaires successifs des documents.

L'rexamen de ces moules, díposés ainsi que le catalogue bismonnot au Vusée des Antiquités Nationales, montre qu'ils sont tous de la même pâte noirâtre et de même facture peu soignée. Ils ont été fabriqués en appliquant de la terre sur des reliefs assez usés ; leur dos n'est pas lissé avec minutie, comme celui des moules de la bonne époque de Lezoux, par exemple. A cette homogénéité de la matiere, s'ajoute le fail que plusieurs moules reproduisent exactement le mêne motif : six masiques (.J. 1). 1:31); deux têtes de Tutelle (J. I). (64), l'une étant restée au Husée de Moulins.

Tout cela laisse supposer que nous avons affaire à un lot de moules trouvés dans le même atelier tardif. Lyon et Vienne semblent bien ètre les deux centres les plus importants pour la fabrication des médaillons d'applique rhodaniens.

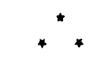

La chronologie des médaillons d'applique de la vallée d’u Rhòne a été établie à partir de trois séries d'observations.

1) Datation par les sujels. La forme litléraire médiocre des légendes métriques de certains médaillons a poussé J. de Wilte et Froehner ì leur assigner une asse\% basse époque, c'est-i-dire le

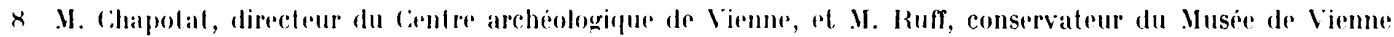
ont bien voulu rechereher s’il existait des comptes rendus des decouvertes du lihamp de Mars ; malheureusement, les rapports les plus anciens semblent posterieurs a cette decomverte. Je les remercie virement de leur aimalule collaboralion. 
${ }_{1 I}{ }^{\mathrm{e}}$ siècle ${ }^{9}$. Plusieurs sujets fournissent aussi un teminus post quem, sans que l'on puisse ètre très précis sur la durée de leur reproduction : Antinoüs, Antonin. Faustine, Géta ; " un relief rappelle une monnaie de Commode (W. A., no 154). Le Génie de Lyon (W. A., no 97 s.) se retrouve dans une pose identique sur un denier d'Albin émis en 196, mais les deux auvres dérivent sans doute d'un modèle commun ». Une chevelure féminine est à la mode de Crispine (W. A., no 73). L'invocation MERGVRIVS FELIX, est gravée au datif sur des monnaies de Postume ${ }^{10} \ldots$

2) Trouvaille dans des siles datés. Elles sont beaucoup plus rares que celles de la terre sigillée et il faudrait continuer un inventaire de toutes les découvertes récentes. On peut signaler qu'í Barbegal, quelques exemplaires tardifs voisinaient avec des objets du ${ }_{11} \mathrm{e}_{-\mathrm{IV}} \mathrm{e}$ (W. .., p. 14) ${ }^{11}$. Déchelette s'était aussi appuyé sur des moules de médaillons trouvés dans les ateliers de céramistes de Trèves et de Cologne, près des fours du ${ }_{11}{ }^{\mathrm{e}}$ siècle (J.D., II, p. 239).

3) Datation par la pâte el le vernis. P. Wuilleumier et $\mathrm{A}$. Audin apportent une série d'observations précieuses, classant les épreuves de chaque motif selon l'usure et l'affadissement des reliefs. Ce classement a révélé une évolution dans le choix et le traitement de l'argile. Alors qu'on employait à l'origine "une belle argile orange-clair, homogène, polie ", on utilise ultérieurement " une terre gris-rosé ou même noire "; de même, la couverte rouge du début fut ensuite "Leintée en noir ou en brun foncé et exposée à des vapeurs métalliques pour recevoir l'aspect du bronze" (W. A., p. 11). Lorsque nous pourrons dater précisément l'évolution des techniques de cuisson dans les ateliers rhodaniens, ces observations prendront une valeur toute particulière ${ }^{11 \text { bis. }}$.

Les trois premières remarques incitaient J. Iléchelette à placer le début de la fabrica-

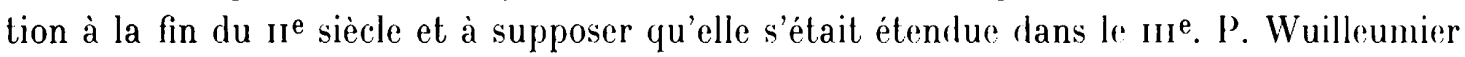
et $\mathrm{A}$. Audin, faute de nouveaux points de repère, se sont ralliés à cette hypothèse. Cess conclusions conservent, certes, leur valeur pour les médaillons considérés, mais les découvertes récentes montrent qu'on ne peut plus les étendre à toute la production rhodanienne.

Un médaillon et un vase de Cologne, étudiés récemment par A. Audin et W. Binsfels, suggèrent au moins pour la période où travaillait le potier FELIX, une date bien antérieure. "Un des reliefs est légendé : HILARITAS POPULI ROMANI, écrivent les auteurs, et doit être de peu postérieur au bronze d'Hadrien qui seul commémore l'Allégresse du peuple romain, bientôt remplacée par l'Allégresse d'Auguste." "Un autre représente, identifié par une inscription, le PORTVS ALGLSTI, et ne doit pas être très postérieur au règne de Néron ${ }^{\text {i2 }}$ " Mais il subsistait un doute : n'étail-ce point la reproduction de formules ou de tableaux anciens? Les fouilles de Lezoux (1963) devaient donner des renseignements inattendus et apporter aux conclusions de MM. A. Audin et W. Binsfeld une confirmation assurée. En même temps que nos amis travaillaient à leur étude, trois fours de potiers étaient découverts sur un terrain de la route de Maringues. Ils avaient été remblayés vers le milieu du II $^{\mathrm{e}}$ siècle, pour établir un dallage, constituant un excellent "ensemble clos».

9 Cilè par J. D., p. 240.

10 Arguments développés par W. A., p. 13-14.

11 F. Bexolt, Revue archéologique, 1940, I, p. 6.1; Informations archéologiques, dans liallia, 19.14, 11 , vase à reliefs d'applique, p. 253, fig. 2, trouve avec des moules de type afticain; - cf. H. Verтtr, Terres cuiles africaines trouvées en Gaule, dans Actes du 86 congrès national des Sociétes sauantes, Montpellier, 1961, p. 42-48.

11 bis M. N. Lamboglia classe certains vases à médaillons lyonnais dans la terre sigilléc claire B : X. LAMBogla, Nuove osservationi sulla "lerra sigillala chiara", I (lipi A e B), dans Rivista di Studi Liguri, XXIV, $n^{\circ}: 3-4$.

12 A. Aldix ef W. Brssfisto, Védaillons dapplique rhodaniens du Muse de Cologne, dans Kölner .Jahrbuch, 1964 , p. 14-17, pl. I. 

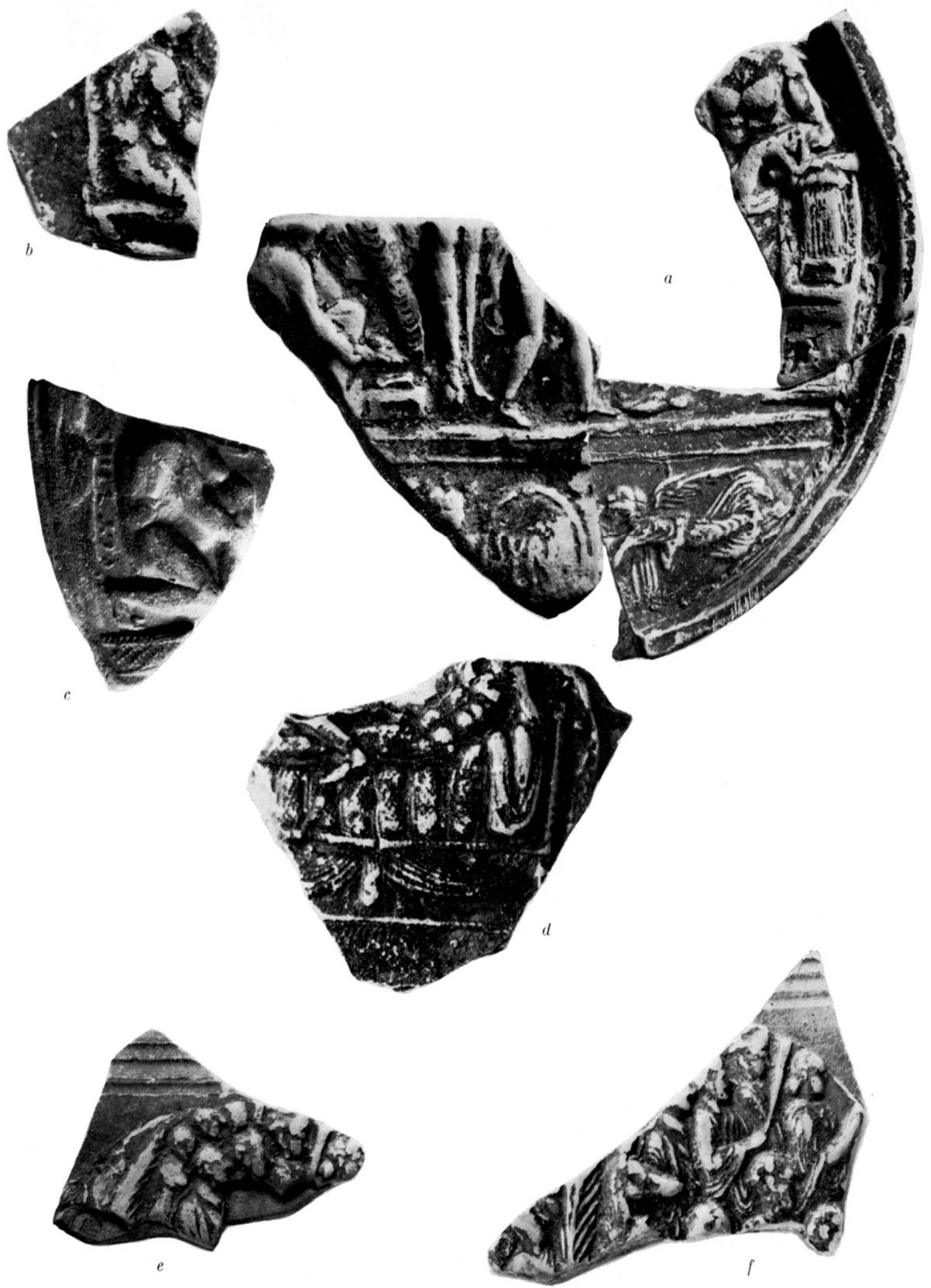

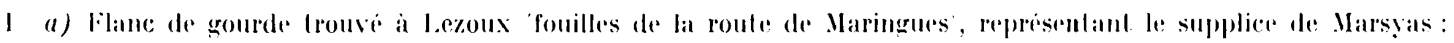

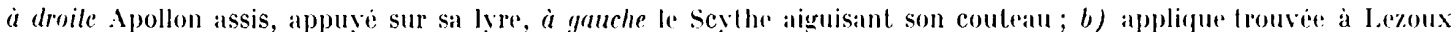
dans le même dépotoir datelier que $a$ : le scçthe est séparé du reste de la scine el appliqué sur un vase, fon 74 ;

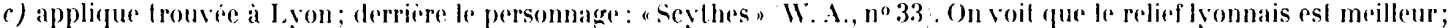
a gauche, le bas du trone diun arthre; d) relief trouve dans le même dépotoir que a ch b: un homme est allongé sur

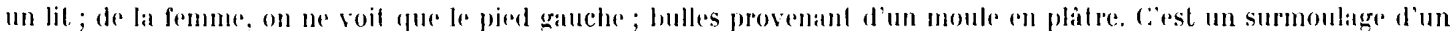

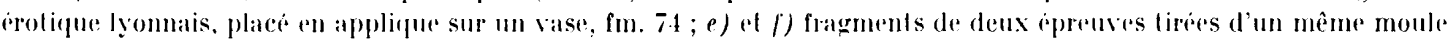
trouvées dans le même dépoloir que $a, b$ ol $d$ : la scine represente un cort lige ; derriere Anubis, une haute palme portere, par un homme. C'est un surmoulage d'une scene du culte isianque, dont loriginal, altribue au rhodanien Flisix, n'a pas incore eli ripertoric. 
Dans la couche de cendre qui était restée collée au fond de la chambre de combustion et surtout dans les angles, ont été trouvés des reliefs d'applique, des lampes (fig. 1 et 14), des vases décorés d' "épingles à cheveux " à la barbotine, et de la sigillée lisse et décorée, le tout de même argile et d'une mème cuisson. Les dépotoirs, en face des alandiers, ont donné quantité de céramiques semblables. Leur date est facile à établir, en raison des estampilles et des décors : nous avons, par exemple, des moules signés I.IBERTVS, BVTRIO, re qui place l'ensemble au début du ${ }_{\text {II }} \mathrm{e}$ siècle.

Dans cet ensemble, il a été possible d'identifier plusieurs surmoulages de productions lyonnaises, notamment :

1) le supplice de Marsyas (W. A., no 43), rattaché à la production du célébre FELIX (fig. 1, a) ;

2) un cortège isiaque, de FELIX aussi (fig. 1, e et f) ;

3) plusieurs reliefs de la veine du premier céramiste érotique (par ex. fig. 1, d).

Nous pouvons tirer de cette récouverte plusieurs renclusions.

a) La fabrication des médaillons lyonnais débute au moins au commencement du règne de Trajan. Il est même possible de remonter plus haut. En effet, pour que les produits des officines rhodaniennes acquièrent une certaine notoriéte, pour que des surmoulages en soient faits dans des centres éloignés de $180 \mathrm{~km}$ environ. pour que, c:omme nous sommes amenés à le supposer, des ouvriers spécialisés aient pu être formés et soient allés s'installer chez les Arvernes, il a fallu vraisemblablement un certain nombre d'années. Ainsi pouvons nous ardmettre que FELIX a commencé à travailler sous Néron ou avant, comme le supposent A. Aurlin et W. Binsfeld.

b) Les deux artistes auxquels on peut attribuer les reliefs surmoules a Lezoux, sous 'Trajan, comptent parmi les plus actifs et les plus habiles décorateurs rhorlaniens, et aussi les plus anciens. Wuilleumier et Aurlin ont remarqué que leur argile est trìs belle, très lisse, celle de Félix va de l'ocre au rose, celle du premier céramiste érolique est rouge ou orange. Certains exemplaires, en terre noirâtre. paraissent tirés de leurs moules par leurs successeurs :W. A., p. 48-49).

Comme les surmoulages de Lezoux ont une surface brun-noir, qui n'était pas connue avant cet apport étranger ${ }^{13}$, il est vraisemblable que les ateliers rhodaniens avaient rommencé à mettre à ce moment-là des surfaces sombres sur le marché. Antérieurement, ils utilisaient surtout la pâte et le vernis oranges mais il n'est pas impossible que les deux coulcurs aicnt été produites en même temps. I)ans le mème dépotoir de Lezoux, dont nous avons parlé, nous avons des sigillées rouges et des vases à applique bruns. Il suffisait au potier de varier la conduite de son feu pour obtenir une cuisson oxydante ou réductrice. Plus tard, au ${ }_{\mathrm{II}}^{\mathrm{e}}$ siècle, une fabrication plus négligée a conduit à un cmploi excessif d'une mauvaise pâte noirâtre. Il y a la une évolution que nous connaissons mal mais dans laquelle nous pouvons déjà placer quelques jalons.

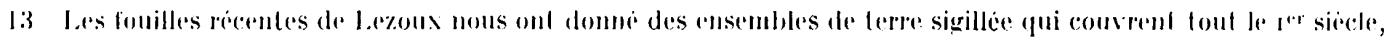
et qui ne comportent que des surfares louges. 
c) Les fabricants de médaillons lyonnais ont eu une premiere période tries belle, très dynamique. Félix apparait comme un des maitres de cellr-ci, peut-être fut-il mème le plus grand.

Il a composé des figures de dieux et de héros, comme Vénus. Mars, Silleanus et IIilarus, Thésée et Ariane, Hercule, Atalante et Hippomène, des représentations de cortèges isiaques. des jeux du cirque. Le nombre de médaillons que l'on peut lui attribuer ne cesse d'augmenter ${ }^{14}$

Pendant de nombreuses décennies. les motifs de cette périodre continuent à ètre reproduits et probablement à ètre surmoulés. Lin mème temps. le répertoirr des ateliers rhodaniens s'augmentait de scènes et de personnages nouveaux. notamment de figures impériales: Antonin, Faustine, Géta. Il y a là une évolution du goùt que nous connaissons encore fort mal ; cependant on peut déjà dire que l'art tardif semble loin d'ètre aussi fin et aussi beau que celui du ${ }^{\text {er }}$ siècle ou du début du II $^{\mathrm{e}}$. A ce moment lá, il a été probablement enrichi par des artistes formes aux écoles de l'art hellenistique du proche Orient (Alexandrie ?) ${ }^{15}$.

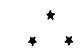

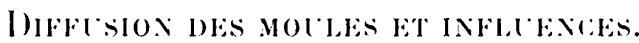

La diffusion des décors et des techniques de fabriration est plus facile a suive pour la réramique moulée que pour les céramiques communes. (ce phénomène économique se produit habituellement selon te schema suivant : des fabriques concurrentes imitent les articles a la morle, en achetant des moules, en surmoulant les objets apportés par le: commerce et, d'un autre còté, des ouvriers spécialisés quittent la maison mère, soil pour aller dans ces ateliers concurrents, soit pour fonder des succursales. Ces processus sont souvent contemporains et entremêlés ${ }^{16}$.

Si une fabrique évolue, regoit des influences et se renouvelle, il an rest dre mème d'un motif. Il se produit, selon les hesoins ou la fantaisie du potier, des modifications dans le décor original, des ajouts ${ }^{17}$, des retranchements, des divisions. Les potiers gaulois daient coutumiers du fait et utilisaient de leur mieux les possibilités d'un relief, d'autant plus qu'ils n'avaient pas de tradition de modelage et devaient tout apprendre. Aussi nous faut-il examiner de près les répertoires des autres ateliers pour déceler l'inlluenere de ceux de la vallée du Rhône.

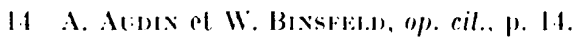

15) Les themes isiagues des médaillons peurent suggerer une origine iggptienne. (On se souvient qu'Auguste a emoyi des colons égyptiens a Ximes el que le culte d’Isis y est altesti. l iexistence dorientaux dautres provenances est allestie, plus lard, a lyon. A la fin du ues., un syren d'Antioche est babricant de poteries dans celle ville. Plus

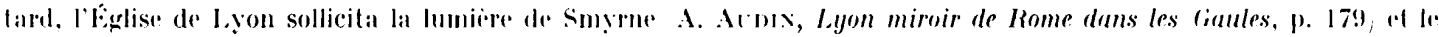

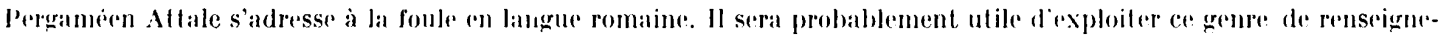
monls pour essaver de priciser de quelle rógion sont venus les potiers lyonnais.

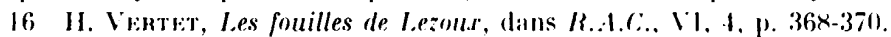

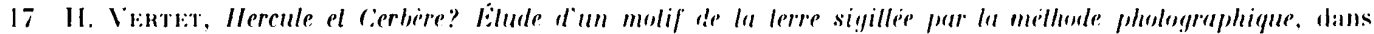

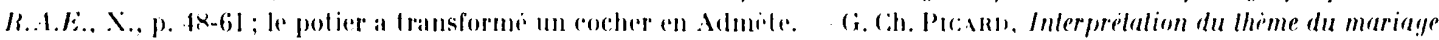
d'Admele, dans Bullelin des Anliq. de France, l960, p. b0); Ies "xemples sont nombremx dans le repertoire gallo-romain. 
On doit se demander aussi si nous pourons attribuer à L yon ou à Vienne des médaillons dont nous n'avons pas encore d'exemplaires dans l'inventaire de Wuilleumier et Audin. Il semble bien que la réponse puisse être le plus souvent positive. En effet, ces deux villes apparaissent comme les principaux centres de fabrication de l'oceident et même les seuls connus actuellement. Comme un répertoire de reliefs ne peut jamais être exhaustif, surtout pour une fabrication dont les ateliers n'ont pas encore été fouilles, on peut supposer avec vraisemblance que, si l'esprit décoratif du document envisagé est de type rhorlanien, l'original provient de Lyon ou de Vienne.

Cependant, il ne faut pas oublier qu'au in siècle, par exemple, la Ciaule reçoit de l'Afrique des vases ${ }^{18}$ et des moules en argile qui se répandent jusqu'aux ateliers céramiques de notre pays. J'ai eu l'occasion de citer quelques-unes de ces importations : des lampes ${ }^{19}$, des vases à reliefs d'applique (Orange, Néris, (Cologne), une statuette peut-être ${ }^{20}$; la liste serait à continuer. Ce qui paraît plus important encore pour notre propos, c'est que l'Afrique n'enroya pas sculement des prorluits manufacturés mais des moules en Gaule, et peut-être même des ouvriers. On a trouvé déjà au moins deux sortes de moules. Les premiers, à Trinquetaille $e^{21}$ a strasbourg et récemment dans l'atelier céramique de Gueugnon ${ }^{22}$. Le Iusée d'Autun en conserve aussi un exemplaire. Leur diffusion parait vaste, car il en a aussi été découvert au moins un en Espagne (Ampurias) et un hon nombre en Italie (Ostie ${ }^{23}$ ). Ils représentent des animaux couchés, d'un style bien particulier et sont datés, par la fouille d'un atelier légionnaire à Caslellum I immidi², des années 198-238. L'Afrique a donne: lieu à la découverte d'une autre série de moules d'où sortaient des médaillons, peut-être des ascilla. Le pourtour est cerné de boudins (un, deux ou trois), le style est souvent assez see cet differe parfois de eelui de Lyon ${ }^{25}$. Ont-ils éte aussi importés en Gaule ? In moule du Musée de Chatillon-sur-seine parait bien appartenir a celte série africaine ${ }^{26}$.

On peut se demander si ces productions africaines ont influencé celles de la ciaule, ¿ partir du ${ }_{1 I}{ }^{\mathrm{e}}$ siecle ; ce n'est pas impossible. Lyon se trouvait sur la voie directe qui partait d'Afrique et allait vers la Germanie. "Arles recoit des produits du monde entier et les envoie vers Trèves", écrivait un contemporain d'Ausone ${ }^{27}$. On ne sait pas non plus si ces médaillons africains avaient trouvé leur origine première dans ceux de Lyon ou si les uns et les autres ont une origine commune. 11 se pourrait que les ateliers africains aient

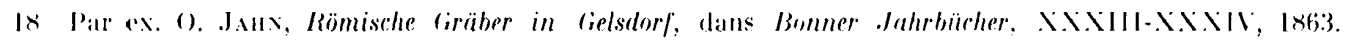

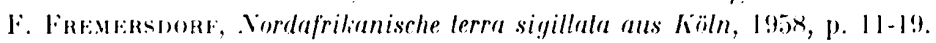

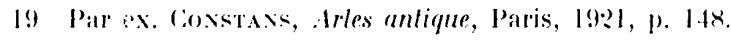

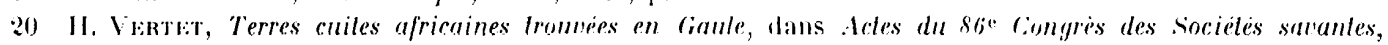
Itontpellier, 1961, p. $11-54$.

21 F. Brosort, ciallia, 1941, 11, 1. 25.4.

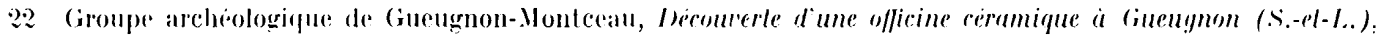
dans I.a Physiophile, no 66, juin I967, figg. 1K.

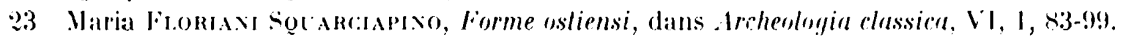

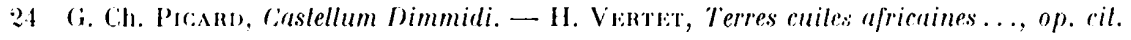

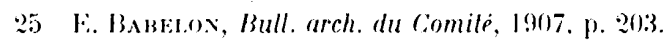

26 A. AıFör.d, Die Alexandrinischen Gïller und die Vola Publica am .Jahresbeginn, dans .Jahrburh für antilie

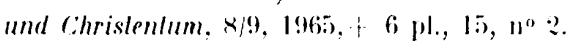

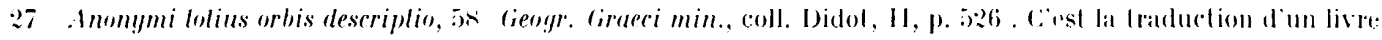

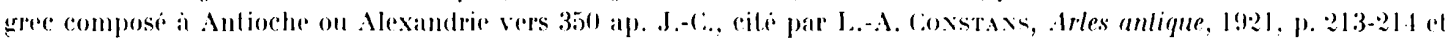
11. 1, p. 214 . 
acquis un style particulier, puis soient revenus l'apporter dans leur pays d'origine. Cela s'est produit avec la sigillée du Surt de la Ciaule, qui a trouvé sa source en Italie, puis a donné en retour des motifs et des formes aux rases moulés de la Péninsule ${ }^{28}$.

Pour ce qui est des atclicrs lyonnais, ils étaient au $\mathrm{II}^{\mathrm{e}}$ siècle et au ${ }_{\mathrm{III}}^{\mathrm{e}}$ siècle asse' bien implantés pour assimiler les influences étrangères, pour en enrichir leur répertoire, pour les faire leurs, mais il n'en était peut-être pas de même pour les ateliers qui avaient reçu quelques moules de Lyon. Il se pourrait que les mélaillons ornés d'une légende circulaire, fabriqués ici ou là et dont nous allons parler, soient dus à une influence africaine.

Ln certain nombre de noms de potiers inconnus à lyon et a lienne ont été releves sur des médaillons ou sur des moules trouvés hors de ces deux villes. Comment les interpréter? Plusieurs cas se présentent:

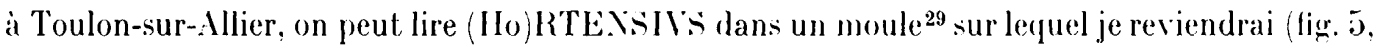
a). Ce nom n'apparaît pas dans la liste des potiers de l'atelier. Sa graphie et sa plare rappellent relles des productions rhodaniennes. Nous avons li, tris probablement, un nouveau nom à ajouter is la liste Wuilleumier-Audin ;

a Lezoux, on lit le nom de sVRILLLis sur un bouclier tenu par deux Victoires, au-dessous d'une scrine représentant le supplice de . Marsyas (fig. 1.a). Or, Surillus est un potier bien connu ì Lezoux ${ }^{30}$, et, la scine a été relevée dans le répertoire lyonnais (fig. 1,c) et altribuée au décorateur FELIXX. (In peut done supposer que Surillus a inscrit son nom dans l'argile fraîche au moment du surmoulage. Cet artisan a-t-il été formé dans les ateliers lyonnais? pour le moment. nous n'en savons rien.

Il faut, je crois, mettre à part une série encore mal connue, comportant autour de la sciene une bande inscrite. On en connaît quelques exemplaires : a Strasbourg, autour du relief (W. A., no 74) on lit ...CANTIVs... (fig. 2,c), nom inconnu à Lyon et à Vienne mais relevé dans les ateliers de l'Est ${ }^{31}$. A Alésia. on vient de découvrir deux morceaux d'un moule figurant Itercule étouffant le lion de Némée, entouré d'une légende (fig. 2.a). Les fouilles du Touring Club de France ont aussi fourni un exemplaire de cette série représentant un cavalier qui fouette son cheval ${ }^{32}$. Au-dessous de lui, deux chiens s'élancent. Une légende, bien eflacée, était inscrite horizontalement au-dessous (fig. 2.b). Nous n'arons point ici un relief d'applique mais le produit d'une autre technique : le potier avait monté une cruche, et. au moment où il avait tourné une bonne partie de la panse. il a imprimé la paroi dans un moule de médaillon en le posant contre l'argile et en appuyant au dos pour faire pénétrer la glaise dans le creux.

Pour réaliser les moules de cette série, il est probable que la bande inscrite a été ajoulée autour de la scene au moment du surmoulage, puisqu'elle entoure des themes dont au moins quelques-uns, sinon tous. semblent avoir été créés, à Lyon ou à Vienne. Celte façon de faire parait tardive; on ne sait pas encore si elle a été le fait d'un atelier ou de plusieurs.

Cerlains moules portent au dos un nom inscrit lorsque l'argile était encore crue. Ainsi avons-nous à (iorsium (Hongrie) DASIVS FECIT sur le moule d'un relief qui parait une variante de W. A., no 73 . el dont les dimentions ont été réduites par le surmoulage ${ }^{33}$. A Cologne, sur des moules de médaillons

ex Il faudrail faire un travail de rechereler analogue pour les medaillons espagunols.

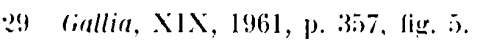

3011 est mentionne dans l'Inder of Pollers' stamps d'oswaten, ot a signi de nombremses lampes fabriquies a I.

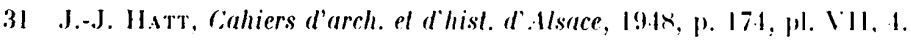

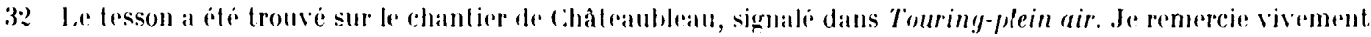
I. Vigrarie, responsable du groupe, de me permetle de reproduire ce beau document.

33 J. Fitz, Gorsium, it Taci Romailiori Asalasok, 1964, p. 49. 


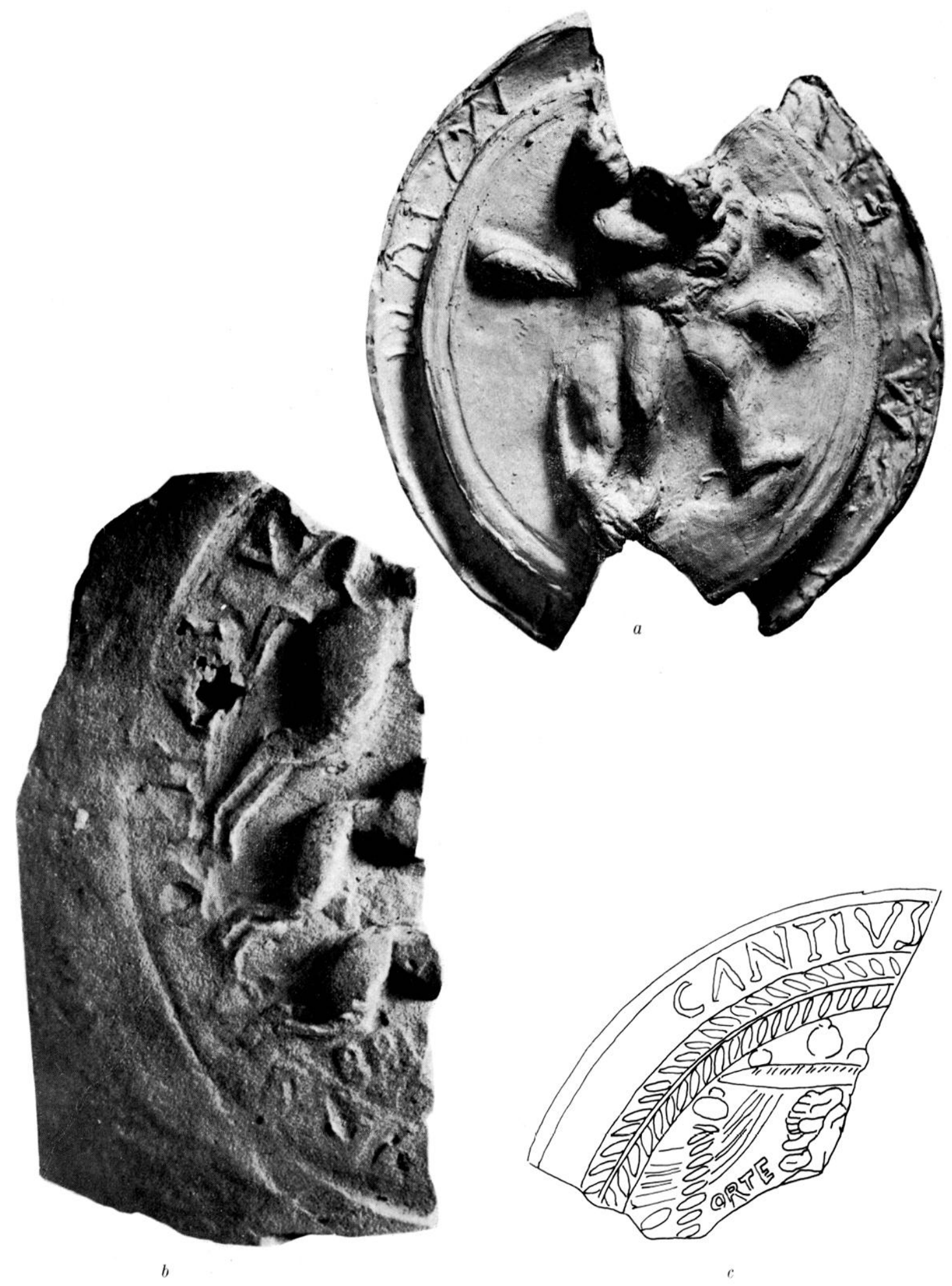

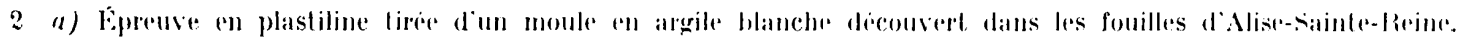

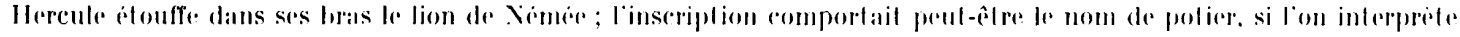

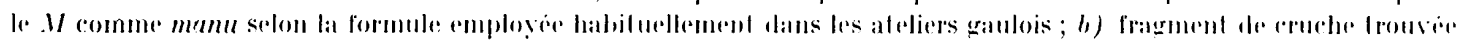

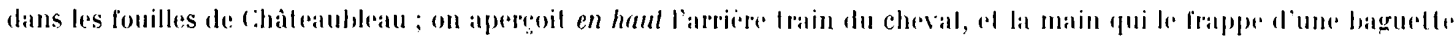

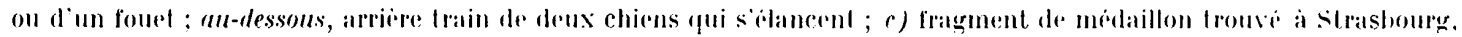

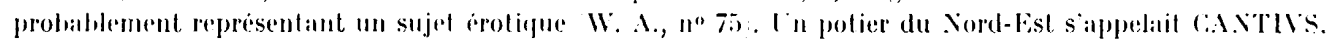



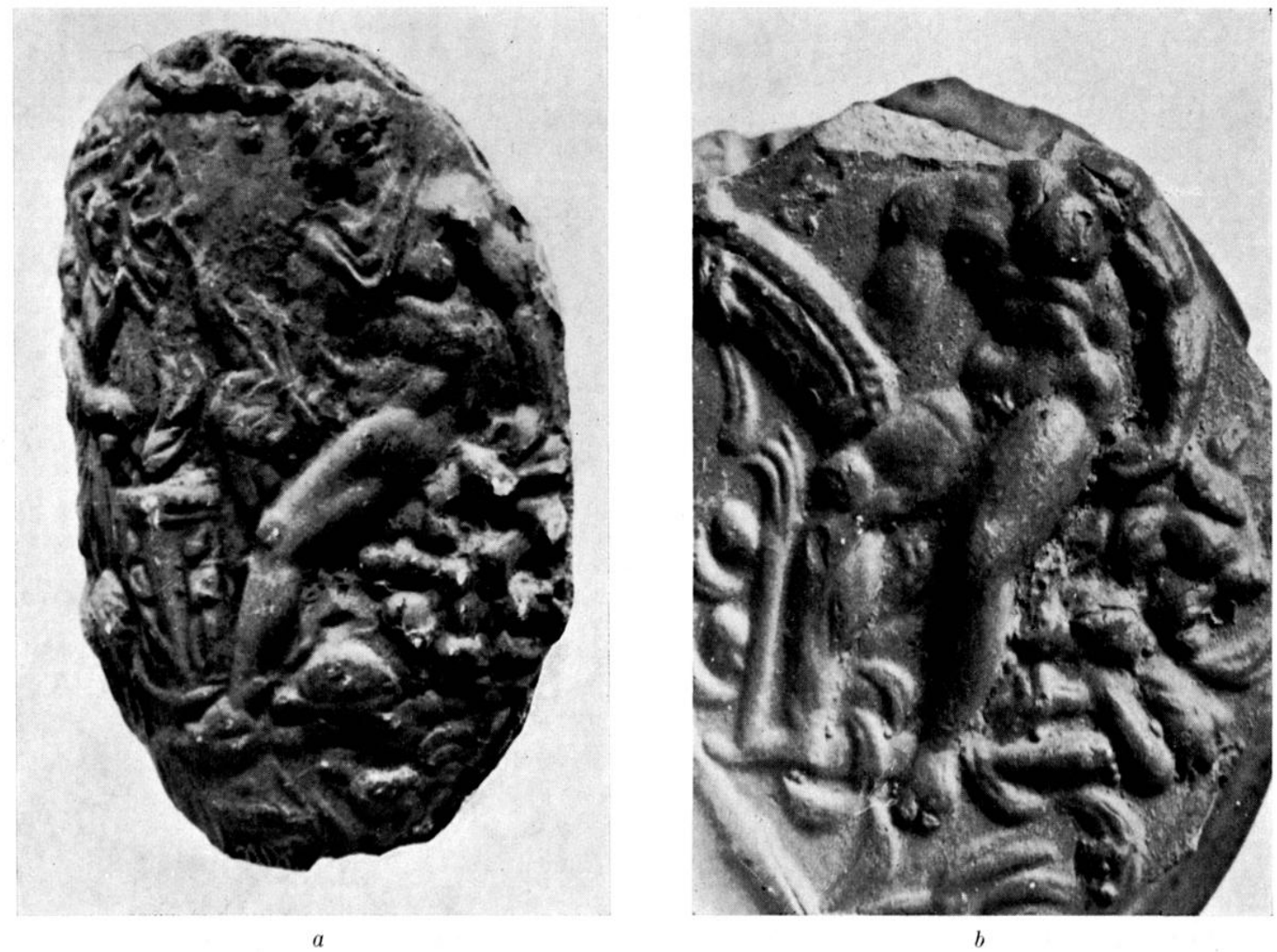

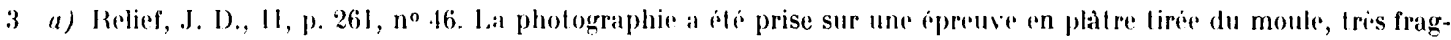
menté Nusée des ant. nat., no 28122 . La hauteur de l'original est de $130 \mathrm{~mm}$; rlle a été réduite pour faciliter la comparaison arec le relief $b$ qui a ele agrandi pour la même raison. La scene représente un sacrifice à Mercure. I'n joueur de flute ef un sacrificateur sont deboul devant un autel quadrangulaire: $b$ ) mort d'Hercule W. A., no 3 i. La dieu est assis sur la peau du lion; les flammes commencent a jaillir. La similitude de la pose des bras du dieu et du héros sont frappantes, de même que les muscles du lorse of de l'abdomen. Aussi semble-t-il que l'auteur des derux reliefs soil le même artisle. On voil metlement les bulles sur le relief de droite.

dont le style rappelle ceux de la vallée du Khòne (Léda. Déjanire emporlée par Nessus). on lit PRIMIIIIVS FECIT ${ }^{34}$, mais nous ne sommes point encore sùr d'avoir en main des épreuves relevées sur des productions rhodaniennes. Les noms inscrits de la sorte représentent, suppose-t-on, l'ouvrier qui a fait le surmoulage ou le patron qui le lui a commandé; il est possible que l'un ou l'autre soit d'origine lyonnaise mais rien ne le prouve.

Une étude trìs précise des emprunts directs au répertoire de lyon el de Vienne par d'autres ateliers reste à faire. J. Déchelette avait signalé seulement trois fragments du médaillon W. A.. $n^{0} 80$ ). trouvés à Vichy et à Lezoux ${ }^{35}$, et un morceau de moule du médaillon W. A., $n^{0} 8: 3^{36}$, trouvi a saint-Bonnet-Yzeure. Wuilleumier et Audin ont rattaché aux ateliers arvernes le J. 1).. n 46, p. 261 , mais cela ne s̈impose pas car c'est un moule trouví

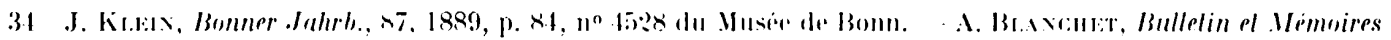
des . Intiq. de firmene, 1x99. p. :2:5. - W. A., p. 16.

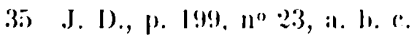

36 J. I)., p. : $:(10), 1^{\circ}: 24$. 
à Vienne, de la même pâte et du même aspect que les autres moules viennois. Le personnage représenté, Mercure assis, est de même facture qu'Hercule sur son bûcher, tel que l'a représenté le Vaître d'Iercule. Les pectoraux et les abdominaux sont identiques, ainsi que la pose du bras bauche (fig. 3, a et b). Il en avait été conclu, peut-être un peu vite, qu'un des céramistes lyonnais "avait transféré dans l'Allier la fabrication d'une série consacrée à l'épopée troyenne $\|^{37}$. En effet, il est possible que les reliefs découverts n'aient pas été fabriqués chez les Arvernes et que le moule de Saint-Bonnet ait été seulement un apport isolé.

De récentes découvertes apportent des documents plus concluants.

Lezoux. Nous avons vu plus haut que des surmoulages d'appliques lyonnaises ont été trouvés parmi les déchets de cuisson d'un four qui fonctionnait à l'époque de Trajan. A la même série doit être rattachée toute une série de médaillons de même facture. par exemple, J. I)., n ${ }^{0} 80$ (p. 215), 81, p. 217). Ils ont été surmoulés à la même époque et appartiennent a l'art de Félix. A une périorle plus tardive, probablement, appartiennent des appliquess à vernis rouge sur vase $(\mathrm{fm} .72)^{38}$, surmoulées aussi sur des prototypes lyonnais. I)ans cette série figure, entre autres, J. I)., n079, p. 214, représentant le supplice de Marsyas, privé des deux Victoires qui volent sous la terrasse. On peut aussi lui rattacher le relief J. I., no 63, p. 209, proche de W. A., no 92, p. 66. Ces deux appliques représentent Hercule étouffant le lion de Némée (fig. 4, c). Leur style, la position des personnages, leurs dimensions (75) $\mathrm{mm}$ de la patte arrière gauche du fauve à l'épaule droite du héros, dans les deux cas) et une façon bien particulière de figurer la fourrure par des touffes de poils. suggèrent un auteur commun, sinon deux modeleurs de la mème équipe.

Ajoutons, enfin, que plusieurs personnages des médaillons lyonnais sont passés dans le répertoire de la terre sigillée moulée. Ainsi Ajax et Hector apparaissent chez le céramiste de l'épopée troyenne sur les bords du Rhône (W. A., no 80, p. 60-61) et ensuite chez les Arvernes (fig. 4, a, b), sur les vases de BVTRIO, qui a travaillé à l'époque de Trajan (fait qui nous confirme la date de fabrication précoce des reliefs rhodaniens) et sur ceux de CINAAMVS (style du (innamus de Vichy; (f. J. I).. V. O. II, nos 122-1223, p. 28). In Silène découvrant Ariane endormie apparaît sur une applique arverne empâtée des pustules 'aractéristiques des produits rhodaniens, puis sur les bols de Butrio et ses successeurs (fig. 4, d). Lne étude en cours a permis d'en retrouver déjà bien d'autres.

Toulon-sur-Allier. Dans un atelier connu surtout pour ses fabrications de statuettes en argile, a été fouillée, en 1960), une grande tranchée-dépotoir. Elle contenait des débris de tuiles, de briques, des fragments de statuettes et de leurs moules, des vases sigillés lisses at décorés, de la céramique commune, parfois peinte et estampillée. L'ensemble date de la deuxième moitié du deuxième siècle. On y a trouvé aussi plusieurs moules de reliefs d'applique. L'un d'eux, à peu près circulaire (diam. de joj a $58 \mathrm{~mm})^{39}$, est complet et de facture

37 IV. A., p. 15.

3x Il est possible que la fabricalion ail commencre plus tol quon ne le pensail. J. D.. p l7u : peut-être pour. rions-mous remonter jusquau regne d'hadrien.

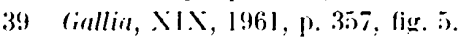



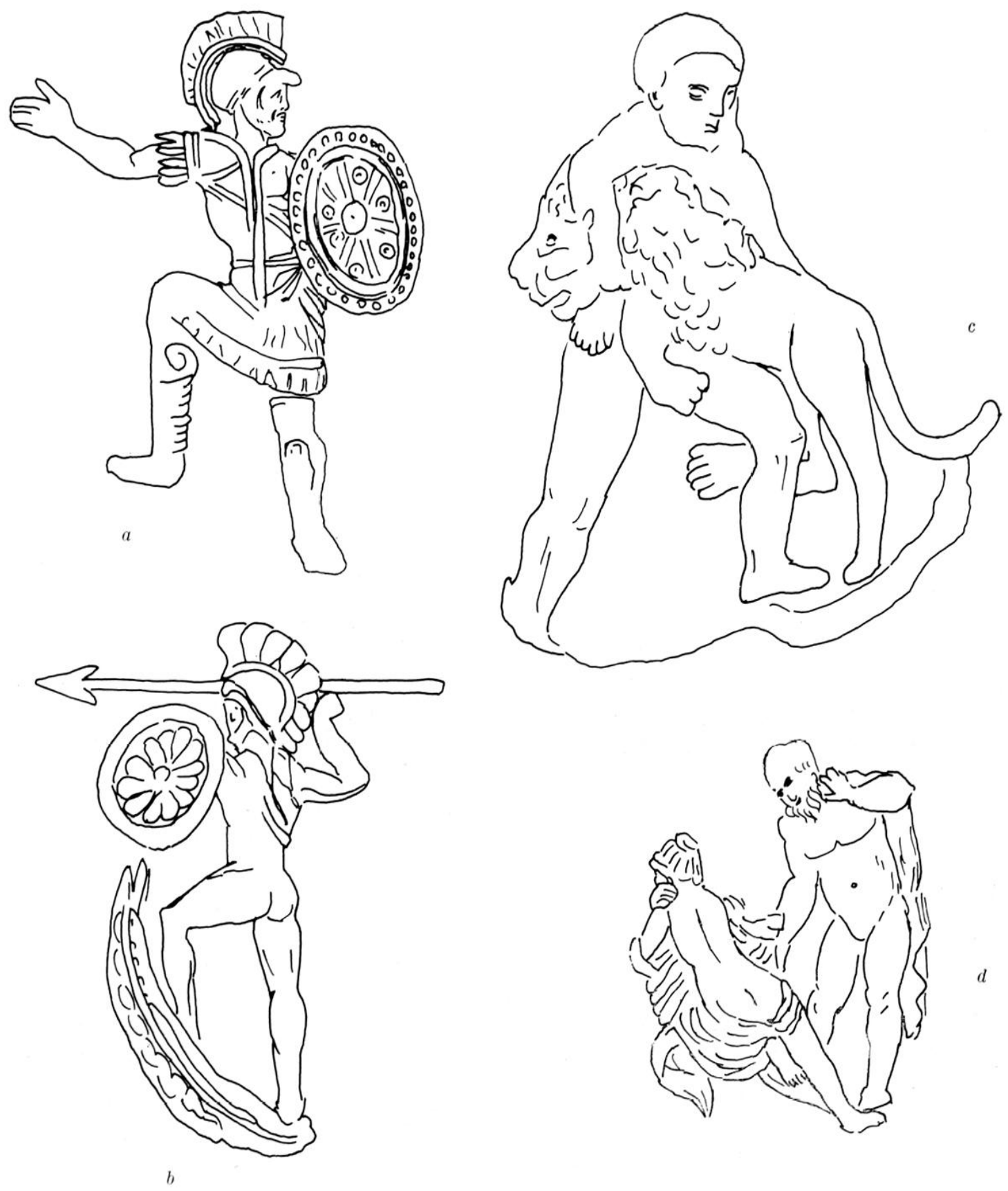

f a) (a b) Heclor al Ajax comballant pris des vaissealux, lires de la scine representee figr. I0. I.es poliers en ont fait des poincons-matrices qui leur ont servi a decorer leurs moules. J. D., II. p. 26, nos ]:22 al 123; ; ) applique sur vase, fm. 72, Hercule elouffant le lion de Nemé J. 1)., II, p. 209, no 6.3; ; l) un Silene decouvrant Ariane; les potiers ont

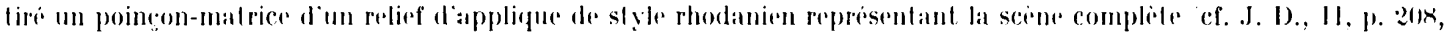
$1^{\circ}: 6 \%$. 
soignée (fig. 5), a). La pâte est blanchâtre; le pourtour a été lissé ; au dos se voient des traces d'empreintes digitales et une encoche; celle-ci parait intentionnelle : le potier savait que, pour placer le sujet d'aplomb, il devait la mettre en haut au moment d'appliquer le moule sur le vase. Le décor représente un lion hondissant. Devant ses pattes de derrière, lo sol est figuré par cinq traits courbes qui se croisent. La crinière est tracée par de grosses touffes, a trois mèches. La fourrure, sur le dos et le long des pattes de derriere. est marquée par de petits traits parallèles; les griffes sont séparées comme des doigts. Au-dessus de la tête du lion est tracée une inscription rétrograrle: (Ho)RTENSIVS. Ce fauve appartient à une scène dont il a été détaché, comme l'indique une légère bordure en relief derrière l'animal, interrompue sous l'avant-train et devant lui. Il est fort intéressant de comparer rette applique avec un médaillon conservé à Vienne (Isère) (W. A., no 92), qui représente Hercule et le lion de Némée (fig. ‘), d). Tous les détails de la figuration du sol et de la fourrure sont identiques, jusqu'au nombre des lignes à terre et à la fine bordure du cardre. Comme nous l'avons dit plus haut, il est probable que (Ho)RTENSIVS désigne un céramiste rhodanien encore inconnu, (à moins que ce soit un personnagre, mais lequel ?). Si l'on considère comme prohante la façon bien particulière de représenter le sol par des lignes courbes, il est possible de supposer qu'Hortensius a fait partie de l'atelier d'Amator, qui a utilisé aussi rette façon de faire: W. A., $\mathrm{n}^{0 s} 112,114,117$. 121 (fig. 5, b, c). Mais il ne semble pas lui avoir emprunté, au moins d'après ce surmoulage. sa couronne de feuilles.

Il est donc beaucoup mieux établi maintenant que les rapports entre les fabriques de médaillons rhodaniens et les ateliers arvernes ont eté durables (au moins pendant tout le ${ }_{1}{ }^{\mathrm{e}}$ siècle) et féconds. Il est probable que l'influence des médaillons d'applique s'est exercée beaucoup plus loin, puisque l'on peut constater des analogies entre les productions rhodaniennes et rhénanes mais. là encore, il faudra étudier les documents de beaucoup plus près. Ainsi la similitude du nom de SERVANI)S', relevé sur deux mérlaillons (W. A.. 204-205) at sur des productions de Cologne, a-t-elle fait supposer que nous avions là le témoignage de l'emigration d'un potier ${ }^{40}$. Malheureusement, les documents ne sont pas probants encore et l'on ne sait point si. en (iaule, SERVANIIS' ne représente pas un gladiateur (W. A., p. 120). Il serait d'autant plus intieressant de suivre cette piste qu'un disque en terre cuite du mème atelier de Cologne porte une légende avee la formule VIENNA FELIX ${ }^{41}$, ce qui établit un lien avec la ville de Vienne.

La vogue des médaillons a traversé l'Europe centrale, puisque nous trouvons un creux surmoulé sur les bords du lanube, en Hongrie ${ }^{42}$. et que l'on vient de découvrir un nouveau moule à $150 \mathrm{~km}$. environ, de la Ver noire. Il a été signalé oralement par le professseur Sultor romme trouvé dans une rouche du $\mathrm{w}^{\mathrm{e}}$ sièclet3. Ce serait aussi un surmoulage du relief IV. A., $n^{0} 73$.

En raison de leur période de fabrication et de la direction des eourants commerciaux,

III 11. A., 1. 16.

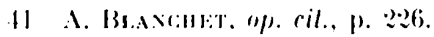

f: Ventionne plus haut : J. Firz, op. ril.

13 Gralement. an Collogue internalional des Amis de la Céramique romaine, à Budapest, en 1967. 


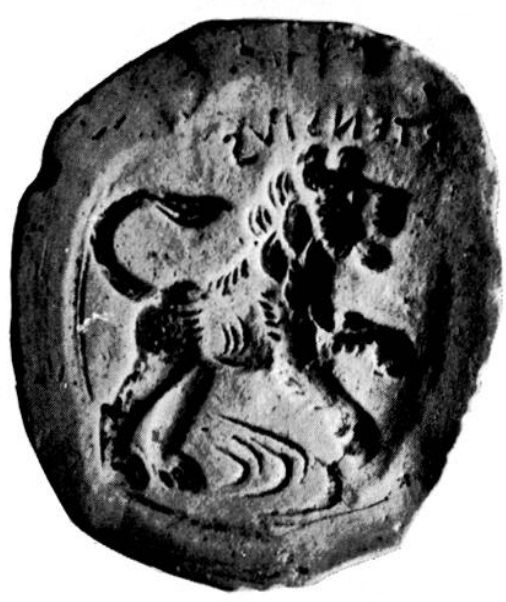

$a$

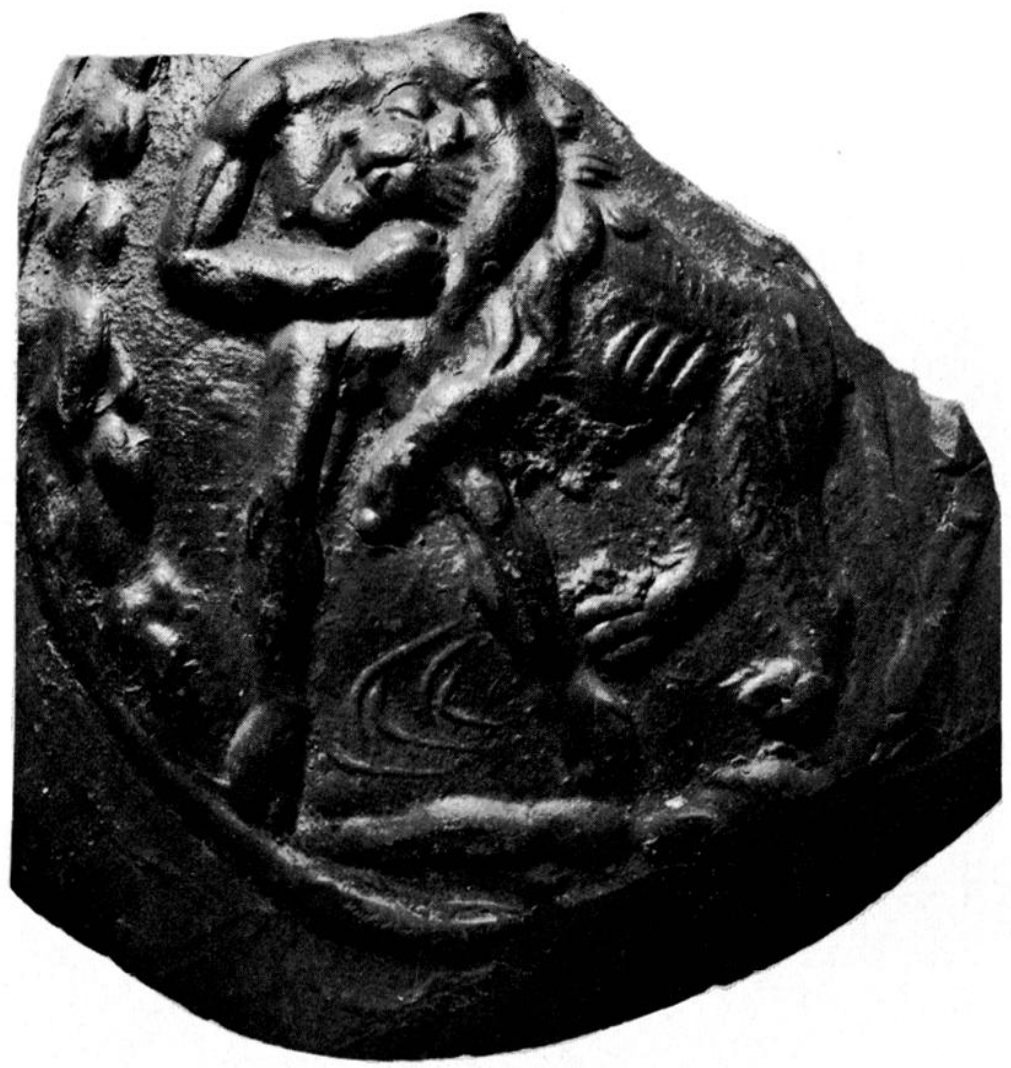

$d$

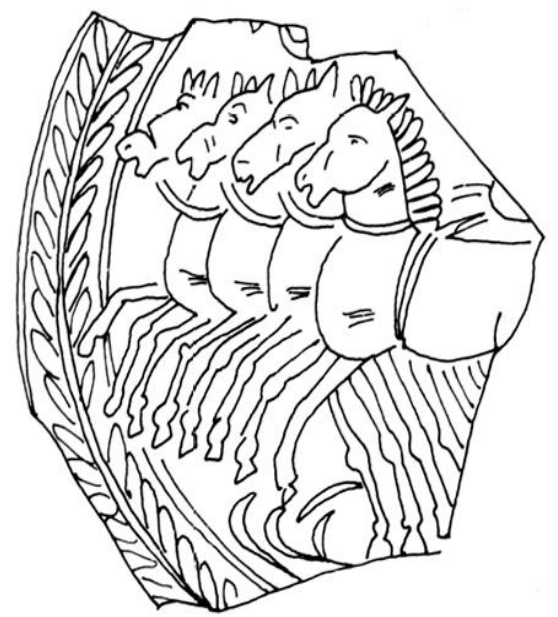

$b$

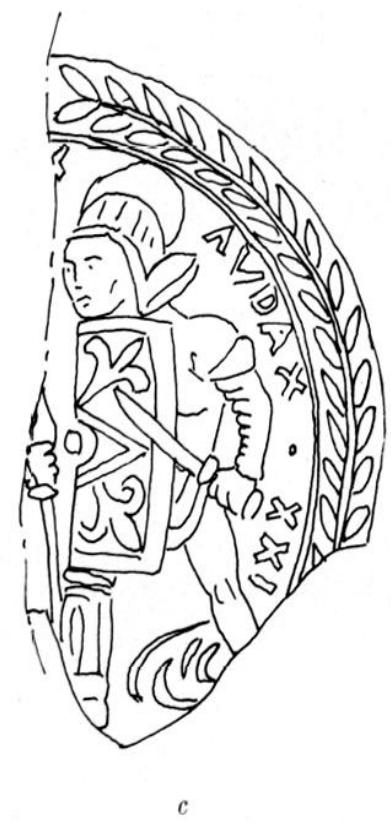

j a) Moule de relief d'applique trouvé dans les fouilles de Toulon-sur-Allier ; en haut Ho) ITTE.YSIVS. Le lion est Iraité dans le même stỵle que celui du médaillon rhodanien représenté en d): mêmés fouffes à la criniere, mêmes griffes aux pattes de derriere, même façon de figurer le sol ; b) et c) quadrige. W. A., no 117) et combat de gladiateurs W. A., $n^{\circ}$ 114) sur des médaillons rhodaniens attribués à AMATOR; la façon de représenter le sable de l'arìne est la même; d) Hercule étouffant le lion de Némée :W. A. no 92); le lion est traité dans le même style que ceux des fig. 4, c, et 5 , d. On remarquera sous le ventri du fauve un empatement dì à la cassure de l'arête du moule en platre. 
il se pourrait bien que les médaillons contorniates et les médaillons danubiens aient trouvé leur origine dans les productions des ateliers lyonnais ${ }^{44}$.

On voit combien la dispersion des reliefs, et l'ingéniosité des artisans de l'époque romaine compliquent notre recherche, puisque nous sommes amenés à rattacher aux productions rhodaniennes des moules et des médaillons qui portent des noms et des reliefs parfois démembrés, inconnus encore à Lyon et à Vienne. Mais cela nous introduit dans un milieu actif et industricux et nous révèle des mouvements d'ouvriers que nous connaîtrions mal autrement.

Pour faire cette étude, il faut noter qu'une caractéristique technique du moulage lyonnais, que nous exposerons plus loin, aide beaucoup à l'identification des reliefs rhodaniens. Il faudra aussi mettre les reliefs ainsi repérés en relation avec les ateliers de la vallée du Rhône et avec les ateliers régionaux, chaque fois que cela sera possible. Il est certain que les analyses de terre, que multiplie M. Picon dans le laboratoire d'archéologie de Lyon, nous seront extrêmement précieuses en l'occurrence ${ }^{45}$.

6 formes des vases à médaillons d'applique rhodaniens : 1) fm. 64 (W. A., p. 9, forme 1). C'est un gobelet tronconique bien connu avec un décor moulé 'par ex. J. D., I, pl. IV) dans la production de LIBERTVS, BVTRIO, etc. Mais il se pourrait que le's fragments interprétes comme appartenant à cette forme par W. $A$. aient plutòt fait partie de la forme 6 . 2 fm. 80 W. A., p. 9, forme 2 et pl. VIIl, 230 a et $69 \mathrm{~d}$ et 80 ) "vase à large ouverture et à panse globulaire, munie d'une ou plusieurs anses fixies au rebord "; 3 fm. 81 W. A., p. 9, forme 3) vase de forme analogue, mais en général moins pansu. Le rebord est mouluré, les anses sont fixées sur la panse ; 4) fm. 77 'J. D., II., p. 236, 237 , fig. $m$ et n, et pl. II, $77\langle 6\rangle$; W. A., p. 10, forme 4 et pl. VIII, 196 a et 159 ) "Vase à col trapu, formant ouverture evasée, et à panse sphérique munie de trois anses et de trois médaillons" ; 5) fm. 79 W. A., p. 10, forme 5 , pl. VIII, 235 c) "vase à long col et à panse spherique. Lin trait sépare le col de la panse "; 6) fm. 75, golelet à dépressions, et muni d'une anse; 7 fm. 63, gourde plate; chaque flanc est forme d'une applique ; le goulot, bas, est accoste de deux petites anses. Cette forme existe aussi recouverte de vernis sigille ou de glacure plombifere. Le decor est alors obtenu par des poinçons separés, des rinceaux tracés à la pointe, etc.

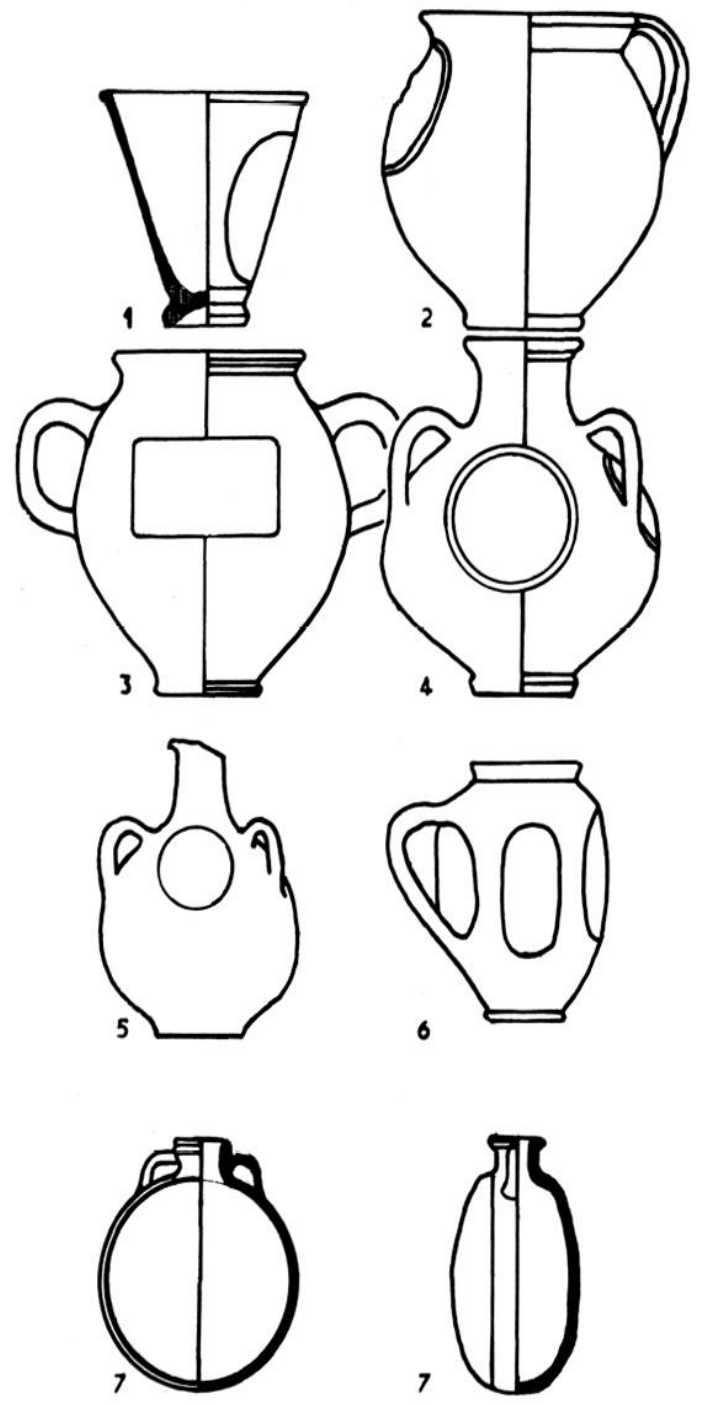

44 A. A1.rö1.DI, Ur-Schueiz, 1952, p. 3, cité par W. A., p. 17.

45 Elles permettront de déceler les mélanges d'argile et les cuissons, qui etaient souvent le fait d'un atelier autant que ses motifs decoratifs. 


$$
\text { ** }
$$

Forme Des vases.

J. Déchelette avait identifié une seule forme de vase et mentionné le rebord d'une autre (J. I).. t. II. fm. $77^{46}$, et p. 246, fig. 5)). Wuilleumier et Audin en ont ajouté quatre. Trois sont des formes ovoïdes, à col plus ou moins ouvert, à goulot parfois élevé (fm. 81). Une serait un gobelet conique (W. A.. p. 9, fm. 64). Il nous est possible d'en ajouter deux (fig. 6).

1) I'n goblel ansé, à dépressions ( $\mathrm{fm} .75)$. Ln exemplaire complet a été trouvé à Paris ${ }^{47}$, (fig. 7, c), un autre à Nimègue ${ }^{48}$ mais, faute de trouvailles dans la région lyonnaise, il était difficile d'ajouter cette forme aux autres; elle pouvait avoir été créée dans les ateliers rhénans, qui l'ont produite abondamment. Quatre raisons permettent maintenant de dire qu'elle a été fabriquée à Lyon.

a) La découverte par un fouilleur local, Jacques Lasfargues, de fragments d'un de ces gobelets dans un dépotoir lyonnais ${ }^{49}$. Il ne reste que la partie supérieure, avec l'épaule du vase, le départ de l'anse et le début des dépressions, mais elle est de la même pâte, « une belle argile orange clair, homogrène et polie" (W. A.. p. 11), que les vases lyonnais de la bonne époque (fig. 7, a).

b) L'existence de médaillons qui présentent la même amorce d'épaule très rabattue vers l'intérieur, juste au-dessus el au-dessous du relief (ex. fig. 7, b, d, e), dans les collections de médaillons altribués sans ambiguïté aux ateliers rhodaniens $s^{50}$.

c) La fabrication de celte forme dans les ateliers de Lezoux, précisément dans les séries influencées par les techniques rhodaniennes ${ }^{51}$.

d) L'existence dans les réserves du Musée de Moulins d'un fragment de gobelet à dépressions ${ }^{52}$ qui porte en applique un personnage sur lequel se voient les perles d'argile, trace du moulage au plâtre caractéristique des techniques lyonnaises (fig. 8, a, b). Ce tesson appartenait vraisemblablement à un vase fabriqué dans les ateliers arvernes.

2) Une gourde plale. Les flancs sont formés de deux médaillons séparés par une surface plane ou légèrement bombée. Elle est munie d'un goulot court, accosté de deux petites anses. On en connaissait depuis longtemps un exemplaire entier, déposé actuellement au Musée des Antiquités nationales (fig. 9, a, b). Il avait été trouvé probablement dans la vallée du Rhône et il porte le nom d'un de ses propriétaires : "vase Sallier» ${ }^{53}$. Il est décoré de deux scènes : la lutte d'Apollon et de Marsyas et le concours d'Hercule et de Bacchus ; la deuxième présente la mention APOLLINARIS CERA. La pâte et le vernis sont les

46 La classification adopté par la réunion du Groupe d’étude de la céramique antique en Gaule, à IDijon, en 1968, evite tous les noms propres devant le numero de la forme : fm = forme orné au moyen d'un moule.

47 A. Hérox ne Villefrosst, Bull. Soc. Ant. Fr., 1966, p. 235.

48 H. Lew.к, Germania Romana, V 2, 1930, pl. XXVII, 7.

4 Dépotoir de Trion.

5) Médaillons du Musée de Lyon el du Musie de Moulins.

5l Il s'agit d'un gobelet à depressions mais non ansé.

52 La pate ct l'engobe indiquent un produit des ateliers de la Gaule centrale.

53 Frofuxier, Musées de France, pl. IIJ, ef p. 12-17; J. D., p. 307-308, et pl. IV. Lec relief n'est pas de tres bonne qualite, il est vaisemblablement ou sorli d'un moule ancien, ou surmoulé sur un original plus beau. 


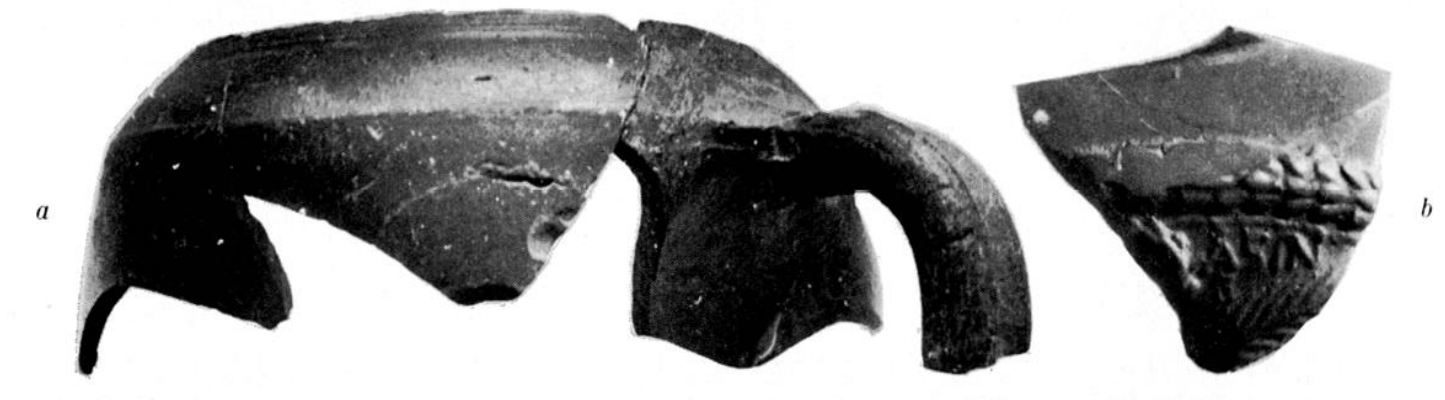

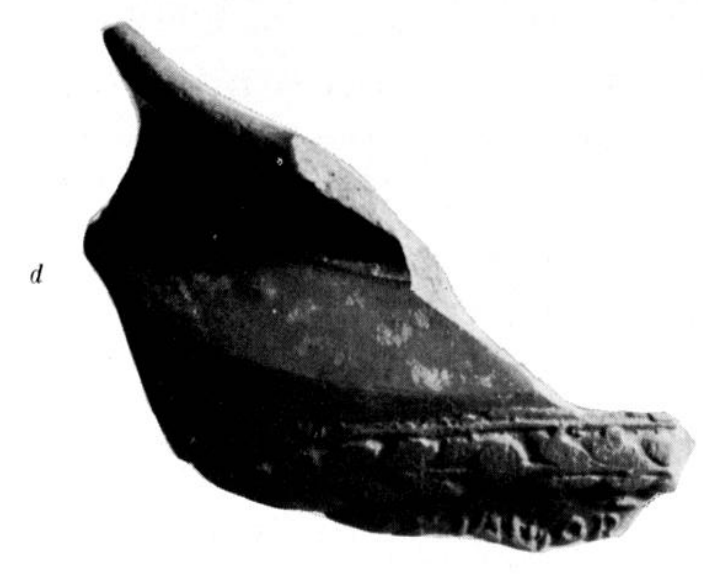

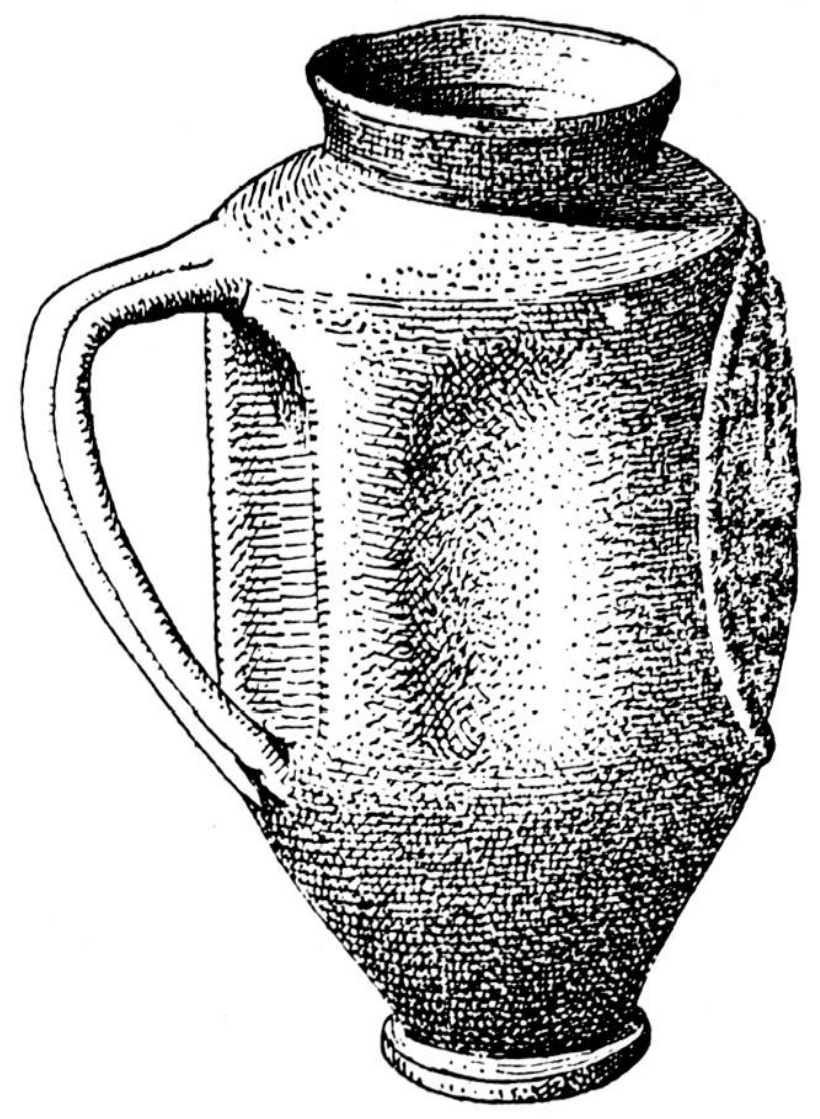

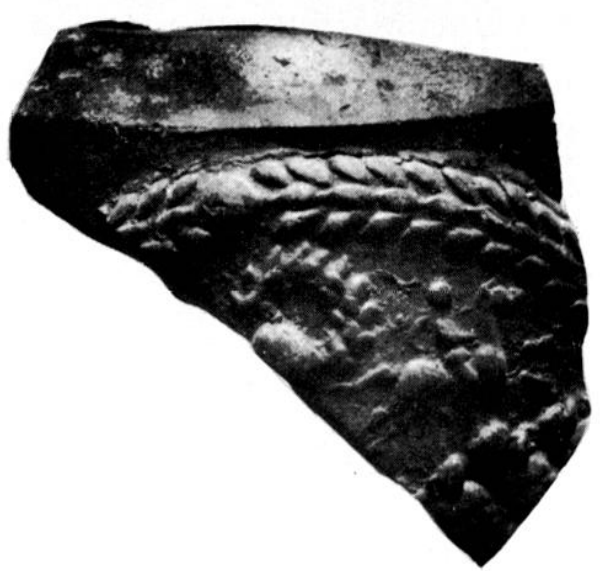

7 Gobrelet à dépressions (min. 75); a) haut de goblelet trouve par J. Lasfargues dans te dépotoir de Trion Lyon; ; b), d), e) fragments de gobelets a depressions des Musées de Lyon ol de Vienne; $c$ ) gobelet entier trouvé a Paris dessin du Bulletin de la siociele nationale des Antiquaires de Frunce, 1906, p. 235). 


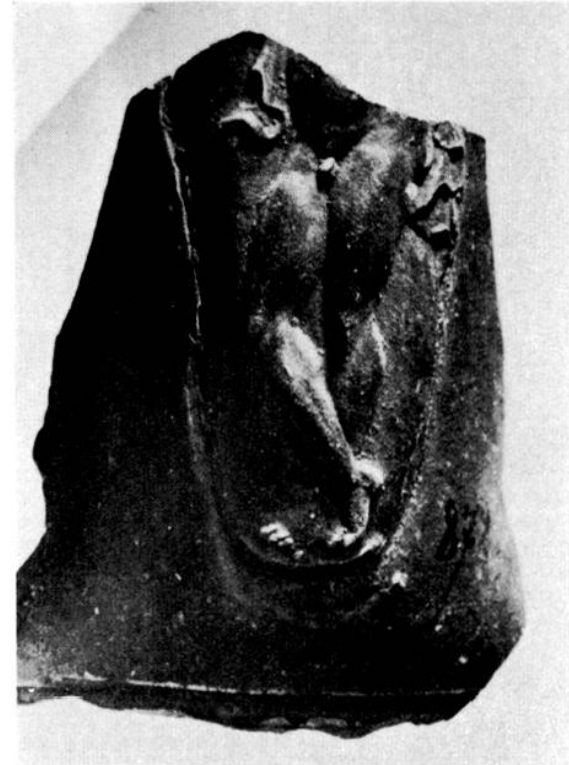

a

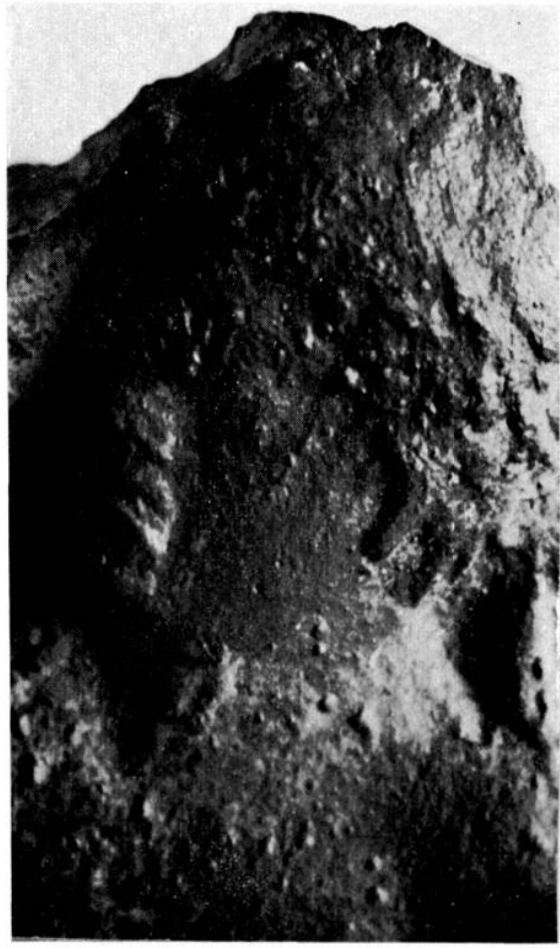

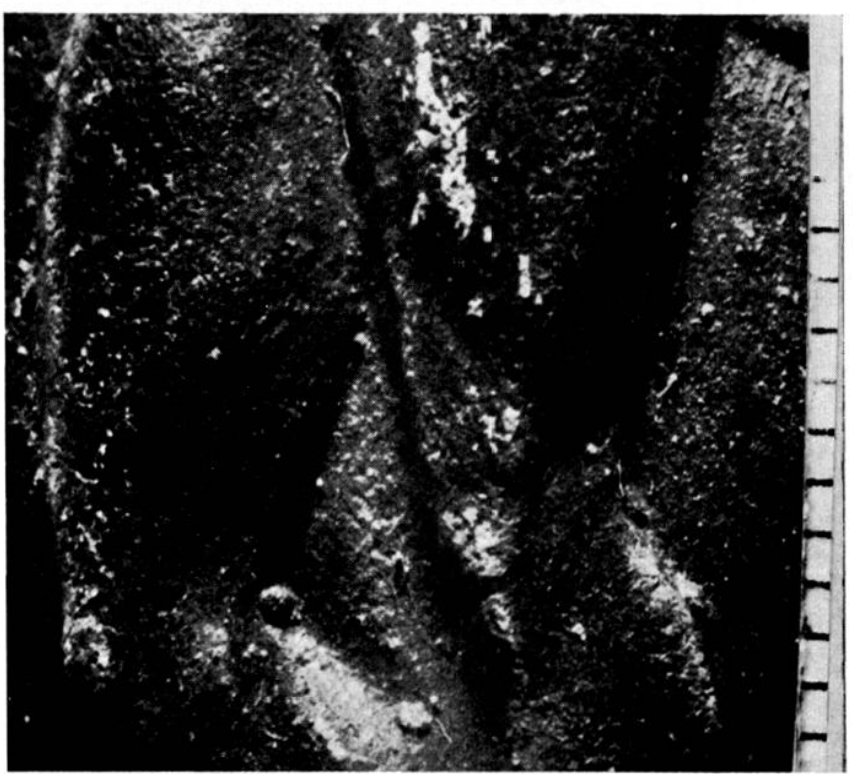

$b$

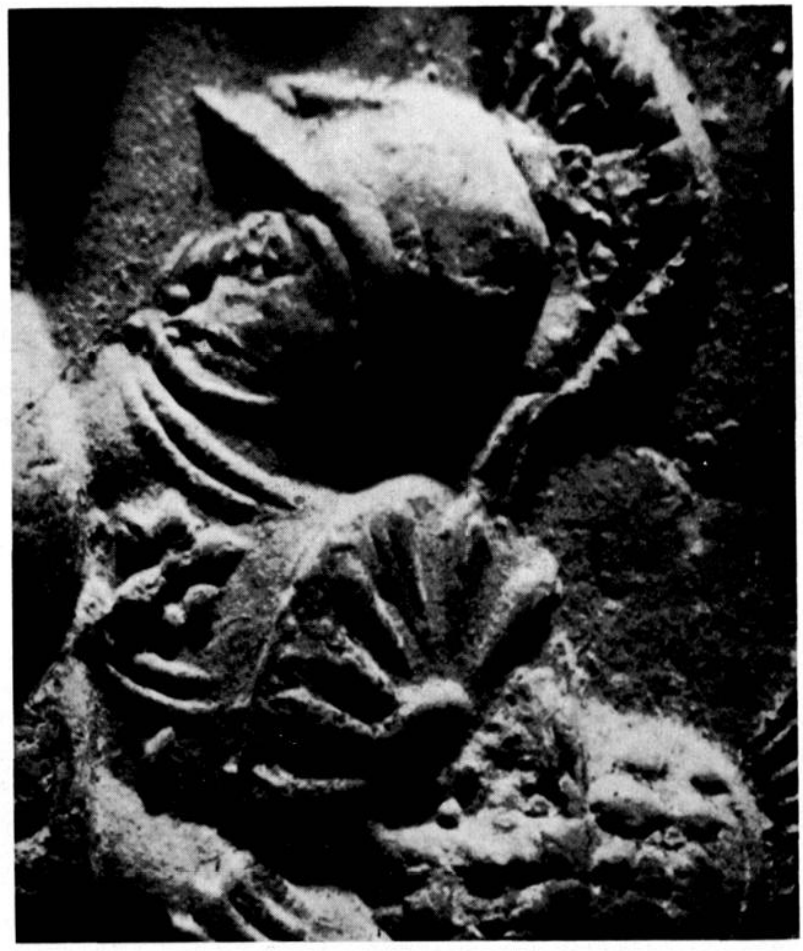

8 a) Fragment d'un golelel à dépressions des réserves du Musée de Moulins ; b) agrandissement de's cuisses et des genoux du personnage. (On voit nettement les perles, provenant des moules successifs en plâtre, les petites etant les plus anciennes; c) tête d'un personnage placé en applique et trouvé aux Martres-de-Veyre tries agrandie), parsemée de perles dues au moulage au platre foulles el collection latournerie; d) agrandissement des têtes de deux guerriers sur un flanc de gourde en terre blanche trouvè à Vichy cf. fig. 10, a, à grauche); on distingue mieux ainsi les perles dues au moulagre au platre et la minulie du travail original. Le relief original a itó réduit par le rétrécissement de l'argile, lors du síchage et de la cuisson. 


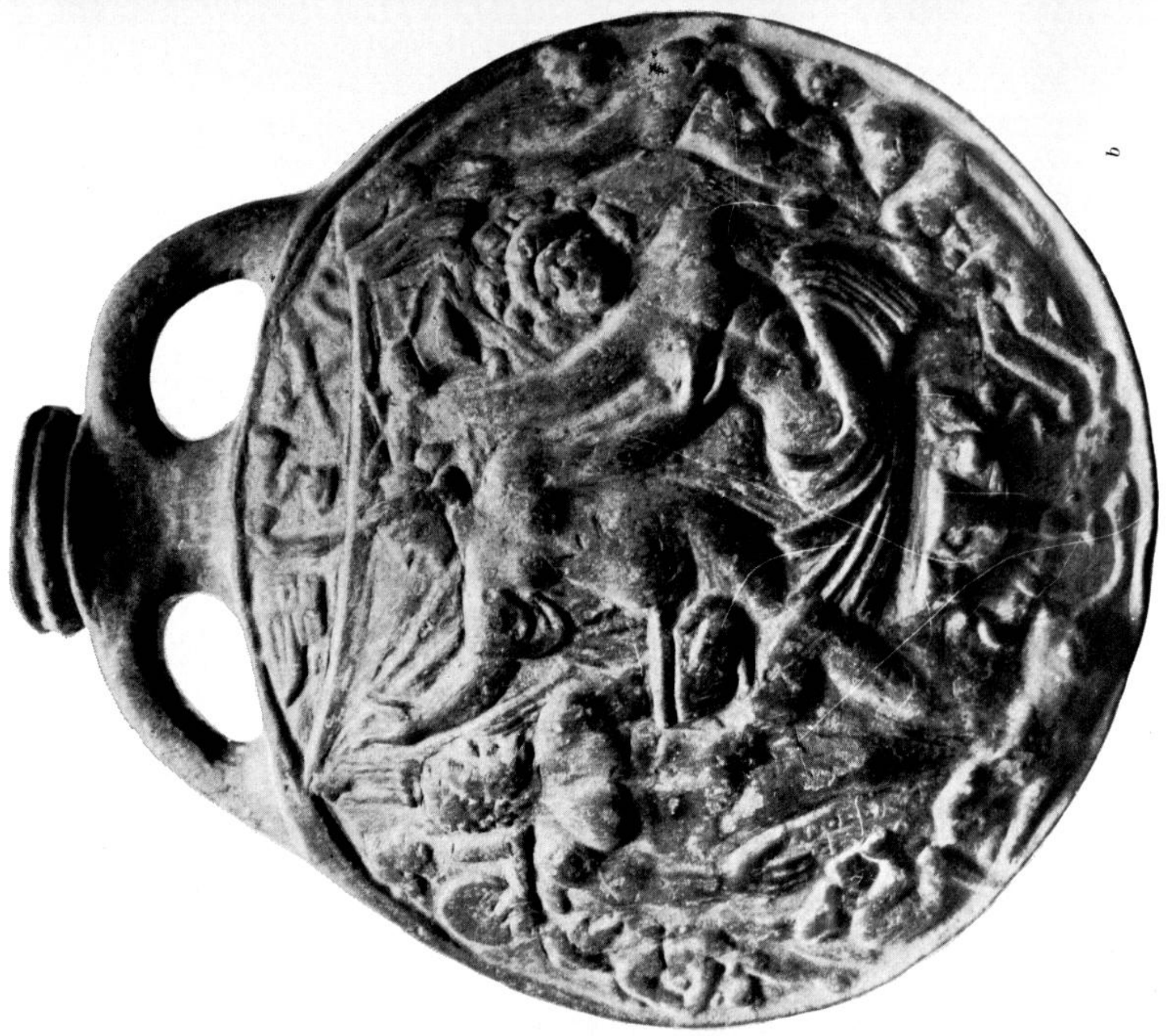

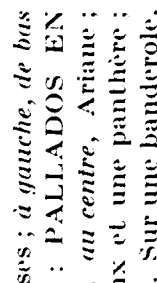

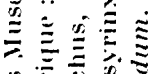

里

穿

की

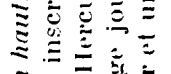

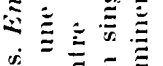

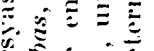

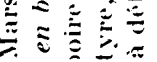

0

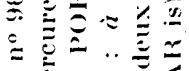

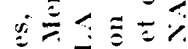

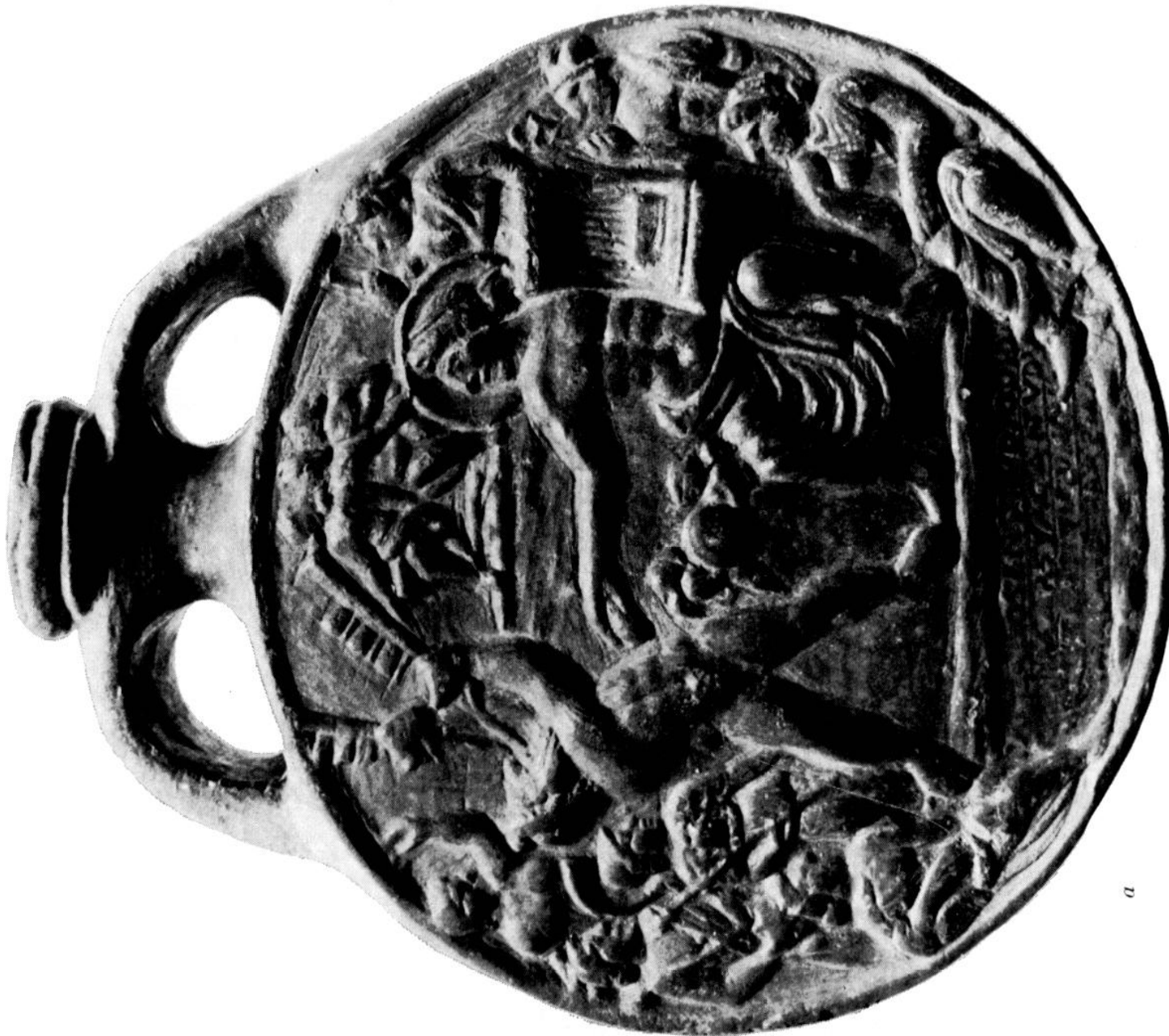

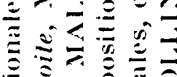

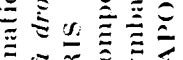

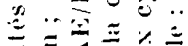

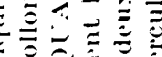

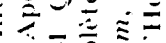

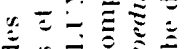

두요

$\underline{\Xi}$

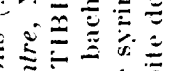

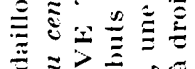

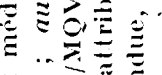

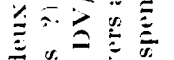

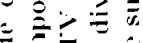

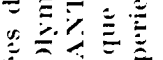

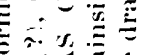

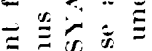

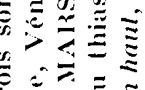

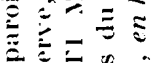

此落。

主要

言

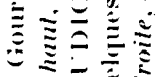


mèmes que ceux des séries rhodaniennes mais aucun parallèle n'avait jusqu'ici permis d'attribuer ce document aux mêmes fabriques que les vases à médaillons. Trois arguments nous permettent d'ajouter cette forme à la liste connue.

(1) La découverte. ancienne, dans les ateliers de Vichy, d'un très beau fragment de flanc de gourde (fig. 10, a et figr. 8, d). Il porte une scène que l'on a aussi en médaillon, avec pâte et vernis rhodaniens (fig. 10, b) : Hector et les Achéens (W. A.. no 80). Ce document avait été signalé par J. Dérhelette de façon erronée, d'aprés Froehner, comme une applique ${ }^{54}$; c'est une plaque d'argile blanche, moulée d'un còté. avec sur le pourtour les traces de collage de la bande médiane de la gourde, et sans aucun arrachement au dos.

b) La trouvaille, en 1963, dans les ateliers de Lezoux, d'un flanc de gourde dont j'ai parlé plus haut, orné du supplice de Marsyas. Il a été fabriqué sous l'influence lyonnaise, comme je l'ai dit. I n fragment de cette scène, de meilleure qualité, a été trouvé à Lyon en applique (W. A., no 33).

c) Enfin, la fabrication de cette forme est attestée dans les ateliers lyonnais depuis le début du $1^{\mathrm{er}}$ siècle. En effel, un goulot en a été trouvé dans l'atelier de la .luette, quai de Serin ${ }^{55}$.

Cela porte donc à 7 le nombre des formes ornées de médaillons d'applique fabriquées dans la vallée du Rhône.

\section{Technigues de Fabrication.}

Des décourertes et des études récentes nous amènent aussi à quelques observations sur les appliques elles-mêmes, sur leur forme, sur les matériaux employés pour réaliser les moules et les prototypes, en un mot sur les techniques de fabrication utilisées par les potiers lyonnais ${ }^{56}$.

\section{Forme des appliques.}

Le diamètre des médaillons varie de 50 à $170 \mathrm{~mm}$ (W. A., p. 9). Il est certain que plusieurs se sont réduits au cours des surmoulages mais les différences sont trop grandes pour qu'il n'en ait pas existé, à l'origine, de dimensions très diverses. Il est vraisemblable que les potiers ont utilisé des reliefs conçus pour orner différentes sortes de vases. En effet, un médaillon plat peut servir pour un flanc de gourde ou un oscillum mais la plasticité de l'argile crue permet de le rendre concave comme un disque de lampe ou convexe pour l'appliquer sur la panse d'un vase ${ }^{57}$. Ce passage d'une forme à une autre est attesté par plusieurs exemples.

54 "Nos dessins sont la reproduction des planches de larticle de Frocher", J. 1)., 11, p. 198, ce qui explique son erreur. Le médaillon :3c, que j’ai relrouvé aussi dans les réserves du Musée de Moulins, est, lui, un médaillon de type rhodanien. Le no 23 d paraît aussi provenir d'un vase rhodanien mais je ne l'ai pas retrouve.

55 Nous n'avons pas retrouvé de fragment de panse. On connaissait déjà cette forme de gourde dans les ateliers de St-Rémy-en-Rollat et de Vichy, recouverte de glaçure plombifiere; dans ceux des Rutenes el des Arvernes, recouverte de vernis sigillé. I.e décor est composé de rinceaux de feuillage ou de la juxtaposition de petits éléments, dans les deux cis.

56 Ces remarques ont été exposces au Journées de la Revue archéologique de l'Esl, à Roanne, en 1963.

57 W. A., p. 17. 


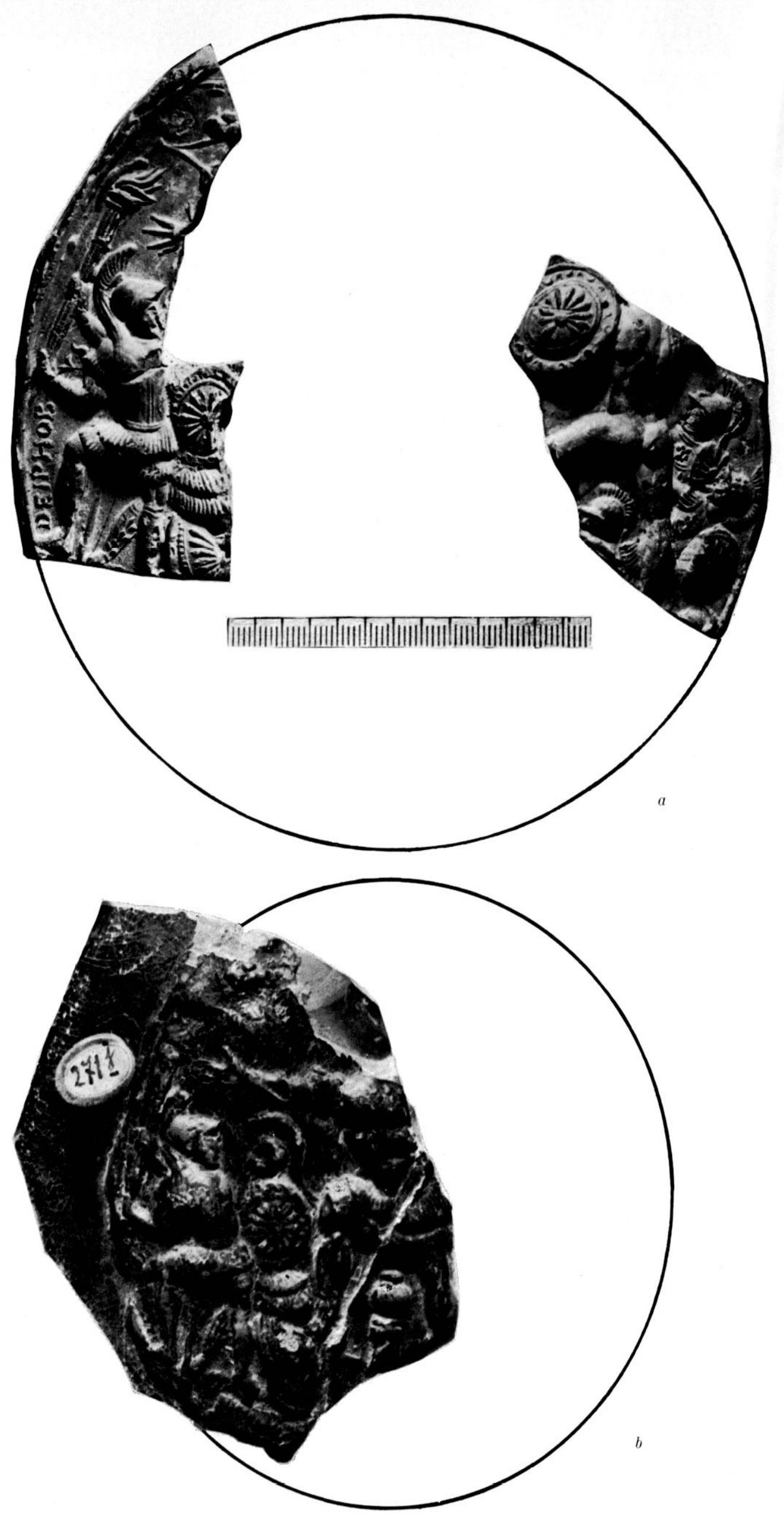


a) Le supplice de Marsyas, dont nous avons parlé, que l'on rencontre : en médaillon sur un vase le Lyon ${ }^{58}$ (fig. 1. c); en flanc de grourde a Lezoux. sous Trajan; en applique sur un vase arverne (fm. 7. . J. I)., n $\mathrm{n}^{\circ} 79$, p. 214); réduit au scythe aiguisant son couteau. en applique sur un vase (fm. 74 . Trajan) $)^{59}$ (lig. 1. b).

1) Ie combat pris des vaisseaux, table iliaque rencontrée : en médaillon (fig. l0, b) sur un vase de Lỵon (W. A. no 80) ; en tlane de gourde (fig. 10, a) a Vichy (J. I)., no 23).

c) Des scènes analogues sur des médaillons de la vallée du Khòne el des oscilla en terre blanche de la vallée de l'Allier. Ils se présentent comme des disques minces. percés de trous de fixation en haut et en has. Les sujets représentés sont, par exemple : les I)ioscures debout devant leurs chevaux (Blanchet, p. 15\%, pl. II. no 23), que l'on peut comparer à W. A., no 174 ; le cyune et léda, Vénus devant une draperie soutenue par deux amours (J.D., I, p. 43, fig. 26 et p. 44. fig. 27); scínes érotiques (par ex. S. Reinach. catalogue illustré de st-Germain-en-Laye, p. 128. no 28059) (par ex. fig. 11, c). Les draperies suspendues au-dessus des personnages, que l'on roit sur de nombreux fragments, malleureusement asse\% menus, trouvés dans l'atelier de Saint-Pourcain-sur-Besbre, sont tout à fait semblables à celles des médaillons lyonnais (W. A., nos 6, 5) (), :1. 144. 149, 198 elc.).

()n a aussi fait un rapprochement entre un médaillon de la vallée du Rhòne (W. A.. no 9 ) avec. l'inscription VIEXIXI/I.IX et un disque en terre blanche cité plus haut trouvé dans l'atelier du

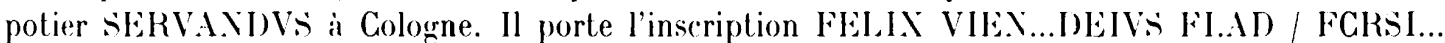
DES.VS et représente une scìne triomphale qui rappelle W. A., $n^{0} 45^{60}$. Toutefois, pour les documents arvernes comme pour ceux de Rhénanie, il ne s'agit encore que d'analogies de style el de décor. L.es fouilles ultérieures nous apporteront, je l'espère, des similitudes.

(1) Des découvertes récentes faites à Lyon ont fourni une lampe ornée d'un quadrige, d'un style proche de ceux des médaillons. Ine lampe du .Iusée de .loulins, qu'on peut attribuer aux ateliers lyonnais, présente une scène proche de celles du premier céramiste érotique de Wuilleumier-Audin (fig. $11, \mathrm{~b}$ ).

La comparaison entre ces différents produits des ateliers céramiques pourra ètre tres utile pour préciser ou confirmer des datations, pour nous renseigner sur les origines et la dilfusion des thèmes ; elle peut mieux nous faire connaître la vie des officines de notre pays, moins spécialisées. la plupart du temps, qu'en Grece ou en Italie ${ }^{61}$.

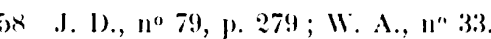

59 Trouve a lezoux, dans le même depotoir que la gourde representaul le supplice de Marssas.

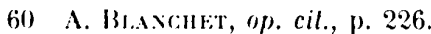

61 Cotle méthode n'a pas ète asse\% employée dans l'etude des aleliers ceramicques de notre pays. Il semble de plus en plus nécessaire d'oludier de front tous les produits fabriqués par un atelier à la mème éporgue.

\footnotetext{
- 10 a) Flanc de gourde Irouve a Vichỵ ; b) relief rhodanien trouve à Vichy. I.es grands personnages sont passes dans le repertoire de la lerre sigiller arverne cf. fig. 4, a, bi. ces representalions de scines homériefues, popularisees par les tal,les iliaques, se retrouvent sur des gemmes. On remarquera ici que le surmoulage a fail disparaitre le nom du

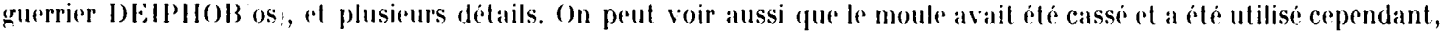
ce qui a laisse une large fissure qui coupe lo corps d'Ajax, en passant au-dessus du poteau à tête sphérique auquel elait amarré le navire.
} 


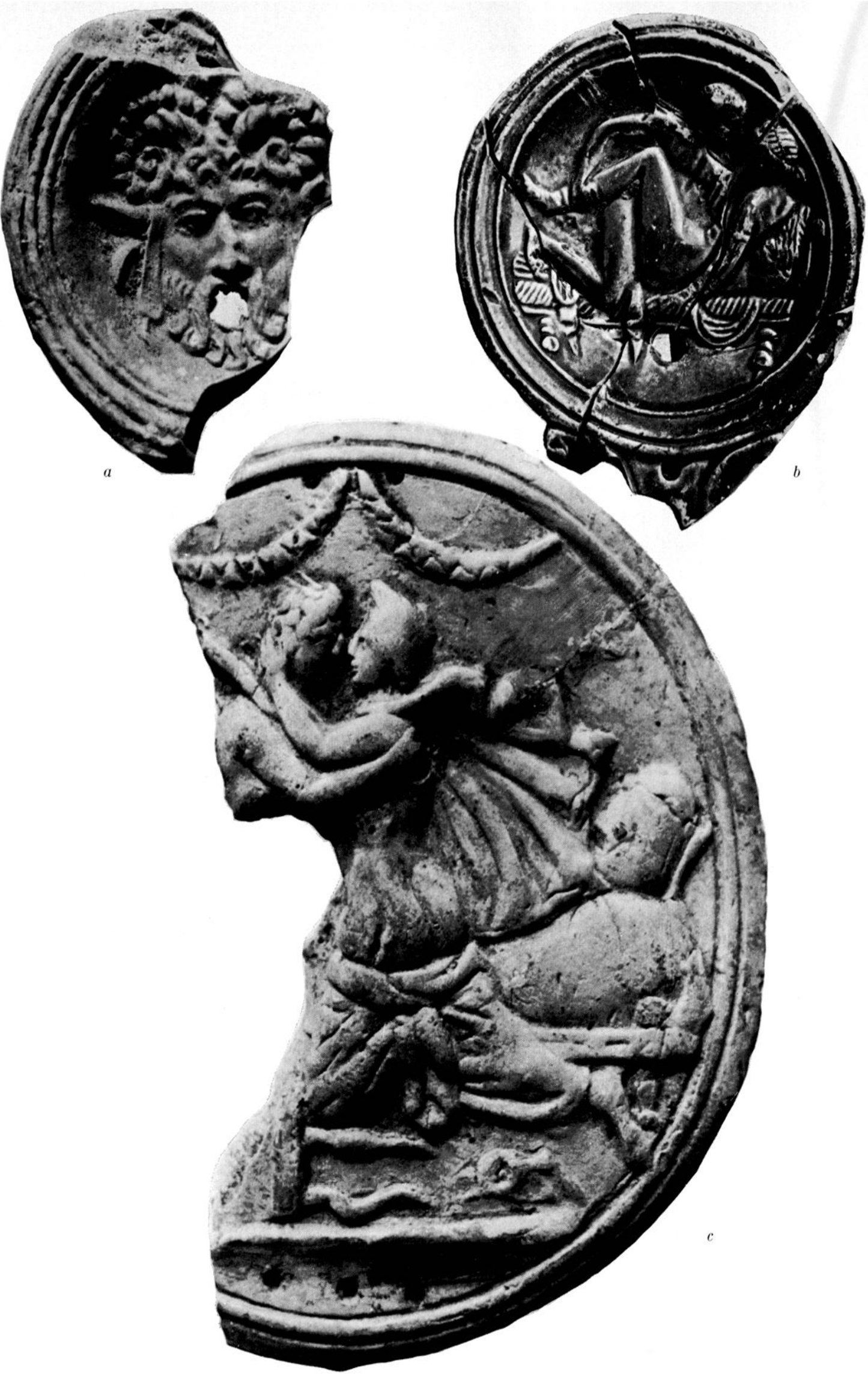

11 a) Lampe figurant un Jupiter Amon, trouvé dans les depotoirs de potiers des aleliers de la Murtte L.von!. On voit que le moulage au plàtre a laissé des pustules, non seulement dans les moulures du pourtour du médaillon de la lampe, mais sur le masfue du dien; b) lampe du Musée de Ioulins : malgré les retouches brulates de l'artisarr pour souligner un relicf usé, on retrouve la veine des érotiques lyonnais ; c) oscillum en terre blanche, des aleliers de l'allier S. Remacin, Catalogue illnstre du Musee des Antiquiles nationales, 1926, II, p. 1:28, fig. 6.3, no 28059). Les guirlandes qui sont en haut rappellent celles de plusieurs médaillons lỵonnais. 


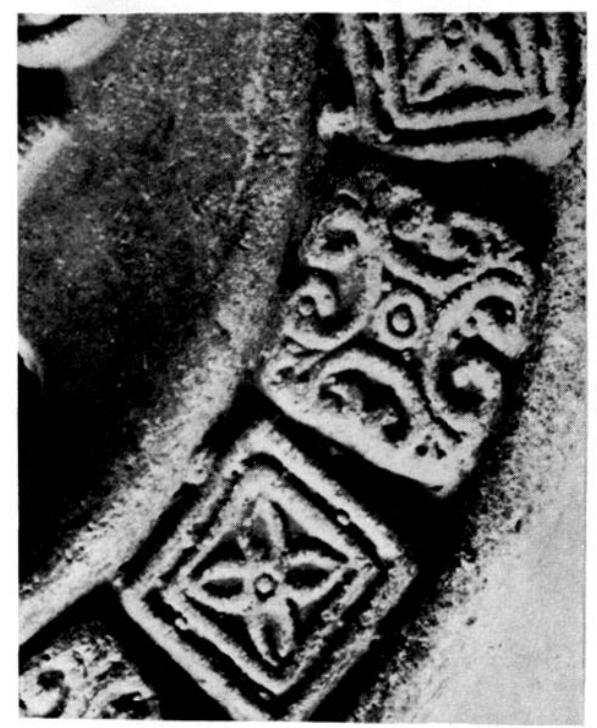

$a$

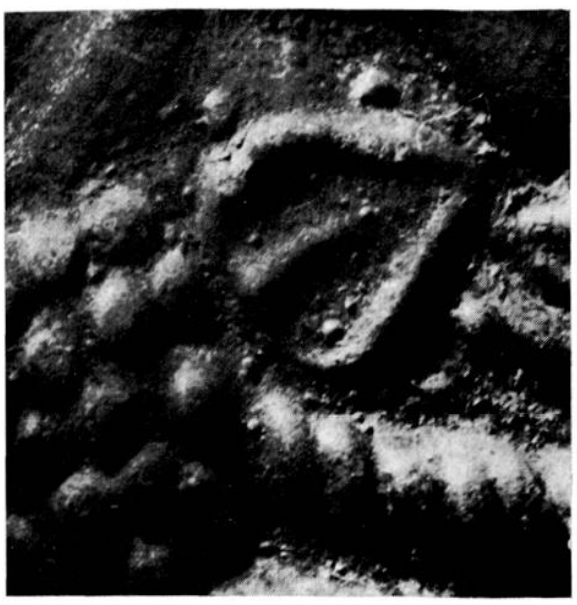

$c$

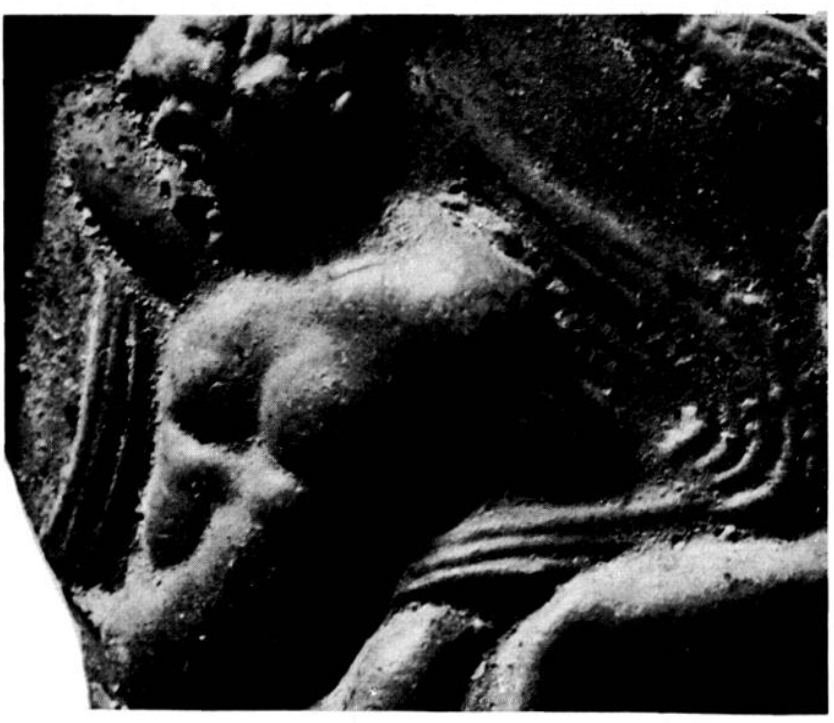

$b$

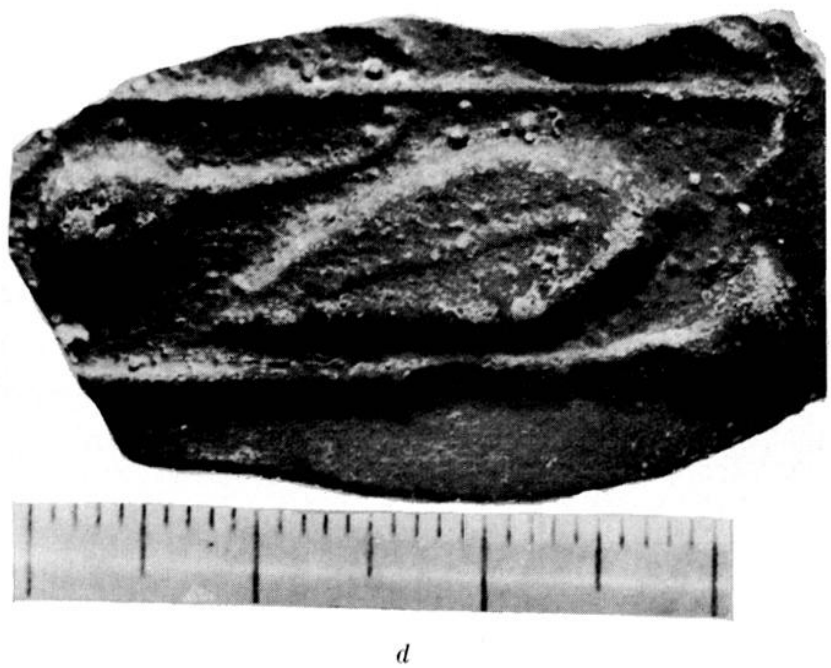

12 Pertes sur des reliefs dargile sortis de moules en platre: a) détail du bandeau d'une lampe africaine; b) détail d'un relief rhodanien W. A. $\left.n^{\circ} 8\right) ; c$ ) détail d'un masque d'applique trouvé à Vienne; d) détail d'un relief d'applique fabriqué à lemoux, trouvé dans le dépoloir d'alelier de la route de Maringues.

\section{Moules de plätre el moules d'argile.}

11 est certain que les solutions apportées aux problèmes techniques de fabrication des moules varient suivant les ateliers et suivant les périodes, les influences apportées par les ouvriers étrangers, les conditions économiques.

Les moules de médaillons lyonnais retrouvés jusqu'à maintenant sont en argile ${ }^{62}$. IIs ne reproduisent que des scènes effacées et ont été obtenus en appliquant, sans beaucoup de soin, de la terre sur un relief déjà usé. Le dos n'est pas lissé. La pâte est brun-noir. 

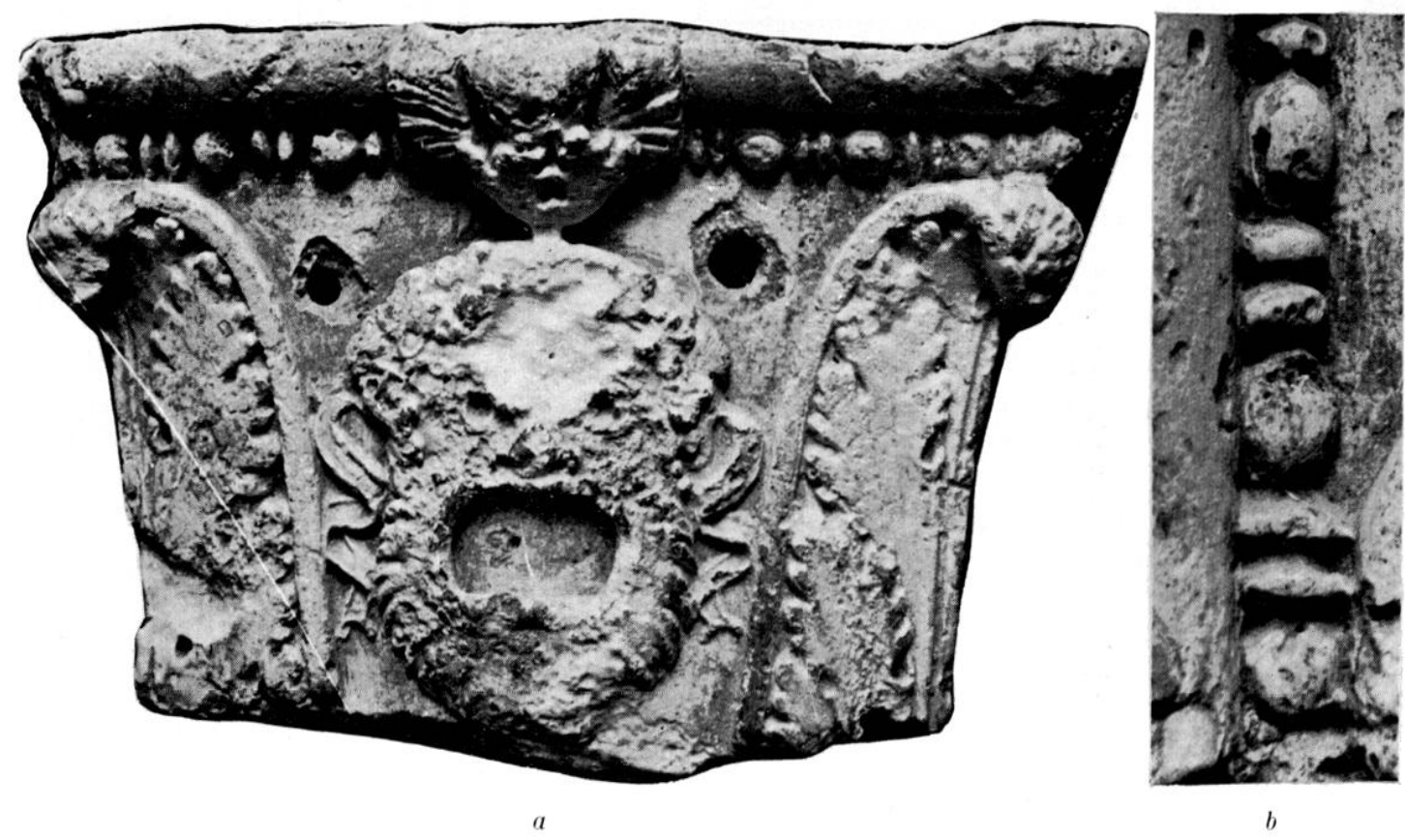

$b$

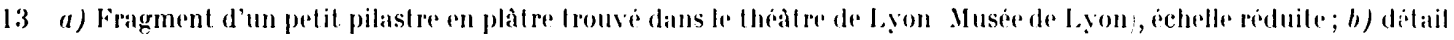
agrandi de la frise, montrant la mauvaise qualite du relief, oi les bulles ont laisse de nombreux alvéoles.

La matière et l'usure montrent que ce sont des documents tardifs (fig. 18, d). Aucun moule de la bonne époque ne nous est encore parvenu. Peut-être n'étaient-ils pas tous en argile.

Si l'on examine les reliefs les plus anciens, notamment ceux qui sont attribués à Félix, on les voit parsemés de pustules. Elles se trouvent contre les membres, dans les plis des vêtements, semblables a des perles. Elles sont la preuve que les ouvriers lyonnais ont d'abord employé le plâtre pour la fahrication de leurs moules (cf. fig. 1, 3b, 5d, 8, 9a, 11a, $12,13,14,18)$. Ces protubérances reproduisent les bulles d'air restées enfermées dans les parties les plus creuses du morlèle au moment du coulage ${ }^{63}$. Les potiers ne prenaient pas la peine de les boucher comme les mouleurs modernes. Il est possible que nous n'ayons pas retrouvé ces creux parce que leur matière se conserve mal sous nos climats humides ${ }^{64}$, mais aussi parce que nous n'avons pas encore fouillé les ateliers de la première période. Cette particularité des médaillons rhodaniens est importante à plusieurs égards :

a) elle pourra permettre de rechercher plus facilement l'origine des potiers qui sont venus s'installer dans la région lyonnaise. En effet. les études de .lme Besque-Mollard. éminente spécialiste des terres cuites, ont permis de savoir précisément que les moules

63 S. Moldarid-Brsq(n, Les lerres cuiles !recques, Paris, 1963, p. 23.

64 Par exemple en Afrique du nord, dans l'alelier d'Henchir-Ks-Srira, P'. (Aat ki.ro, Bull, arch. du Comile, 1905,

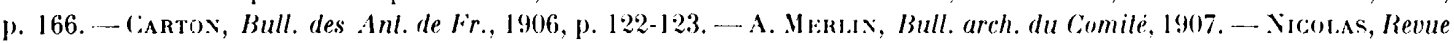
Tunisienne, 1967, p. 449. A Oudna, Tunisie, on a trouve non seulement des moules de lampes, mais d'autres formes de

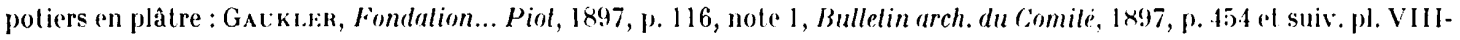
IX. -- Calalogue du . Musée Alaoni, 1897, p. 252-253. 
en plâtre ont connu une grande vogue à l'époque hellénistique et surtout à l'époque romaine, dans trois centres : l'Asie-Vineure gréco-romaine (Smyrne, Tarse), l'Égypte et Rome. Il resterait donc à examiner si, dans ces régions. se trouvaient des fabricants de médaillons $s^{6}$.

Lin masque mortuaire en plâtre et une applique architecturale (fig. 13, a, b) trouvés à Lyon montrent que ce matériau y était employé par d'autres artisans que les potiers.

b) La présence de ces perles sur les produits moulés de Lyon et de Vienne peut servir à étudier l'essaimage des ouvriers et la diffusion res techniques utilisées dans ces deux villes. Dans aucun autre atelier de la Gaule, je n'ai trouvé un emploi du plâtre aussi généralisé. Le défaut des perles apparaît sur les médaillons comme sur les lampes et se retrouve au loin, à travers les surmoulages d'argile qu'on en a fait dans d'autres officines. Ainsi m'a-t-il déjà permis de confirmer la venue d'ouvriers rhodaniens à Lezoux sous Trajan, apportant leurs techniques et leur style. Le dépotoir de la route de Varingues, comme je l'ai dit plus haut, nous a donné des surmoulages de reliefs de Félix mais aussi des lampes (fig. 14, a, c), dont la fabrication s'est mal acclimatée dans ce pays sans huile. Il nous a donné aussi une grande quantité d'appliques plus petites que les mérlaillons mais d'un style excellent et toutes couvertes de pustules dues au moulage au plâtre. Comme la matière, la cuisson, le vernis sont exactement les mèmes que ceux des surmoulages rhodaniens irréfutables, nous sommes amenés à enrichir le répertoire lyonnais d'une production qui ne lui avait pas encore été attribuée. ('es mêmes pustules apparaissent sur des reliefs de Vichy et des Martres-de-Veyre (fig. 8, (c), elc.

c) On peut se demander pourquoi les potiers arvernes n'ont pas adopté cette technique et lui ont préféré la fabrication de moules en argile. Ce n'était pas l'absence de gypse car il en existe des gisements très apparents non loin de Lezoux, par exemple, gisements exploités depuis très longtemps. On pourrait supposer que les artisans gaulois ne savaient pas raffiner le plâtre pour le faire servir au moulage ${ }^{66}$. Ils n'avaient pas une longue pratique de la reproduction des reliefs comme les potiers méditerranéens. Il est possible aussi qu'ils soient spontanément restés fidèles à la tradition des potiers arétins, qui n'utilisaient que l'argile pour leurs moules. Ni à Arezzo, ni en Italie du nord, ni chez les Rutènes, ni chez les Arvernes, il n'y a de bulles semblables sur les vases moulés, ni sur les figurines, à ma connaissance tout au moins.

65) S. Moldarn-Besole, les Terres cuiles grecques, p. 23. Lauteur souligne cerlaines caractéristiques de ces fabriques qui se retrouvent dans celles de Lyon : p. 89-92, à smyrne, le style est celui des bronziers et les figurines sont. recouvertes de belles glaçures rouges ou de glacures plombeuses vertes, jaunes ou brunes; p. 95, à Tarse, où les seuls moules decouverts sont en plàtre el, à en juger par les nombreuses "perles" qui demeurent sur les terres cuites, les moules en argile devaicnt être en minorite... ". A Tarse, Courly signale dans les ateliers une tradition de reliefs d'applique dont les moules ont det trouves: F. (осния, Les vases grecs à reliefs, 1922, p. 477. Malheureusement, nous sommes en général assez mal renseignés sur ces produils orientaux de l'éporfue romaine. Lees prétendus "moulages " ou " modeles " du trésor de Bégram, en platre, ecrit Ch. Picard, sont souvent des oscilla: Ch. Picaro, Comment traiter méthodiquemenl des arts hellenistiques, dans Revue Belge de Philologie el d'Ilistoire, XXXIX, 1961, 1, p. 14, note 2.

66 J'ai exposé ce prohleme au Congres de Koanne de la K.L.E, tol dans ma these, Calalogue des lampes antiques du Musee de Moulins, chapitre III, 3, emploi du platre a paraître! 
14 Lampes et reliefs arvernes trouves dans le dépotoir des ateliers, route de Haringues I, (ooux sauf $g: a)$ lampe décorée d'un taureau qui se retrouve sur $b$ relief d'applique de vase, fm. 7f; $c$ ) lampe signéc SVIRIII.I comme a et comme le flanc de gourde (fig. $1, a ; b, d, e, f, h$ sont des appliques sur vases, fm. $74: d$ ) Bacchus jeune; $e$ ) couple amoureux dérivé d'Amour et l'syché $(J . J) ., ~ I I, n^{0} 46$, ici on voil la terrasse sur laquelle sont les personnages el les rivets placés en rectangle; sur l'exemplaire donné par J. D., ils sont placés en ovale ; f) masłue (Gorgone ?j ; fl) medaillon lyonnais du Musée de Moulins W. A. n 169 ) : on peut comparer la facon dont sont faits les genoux des chevalux sur !f et sur $h$, applique de Lezoux 'J. D., II, p. 232, no 146): les boules en relief semblent avoir ale lracées en creux avec un trepan. Les perles provenant du moulage au plâtre indiqutut, à l'origine, un atelier lỵonnais, dans les deux cas. 
d) Enfin, on peul se demander à partir de quel moment et pourquoi les potiers rhodaniens sont passés des moules en plâtre aux moules d'argile. ln examen, encore trop rapide, des médaillons que j'ai pu avoir sous les yeux, me semble montrer ceci : pour les médaillons les plus anciens et les plus beaux, le plàtre était raffiné et les bulles sont rares et petites ; plus tard, le soin apporté diminue et l'on a des pustules nombreuses et assez grosses; puis, on passe au moulage à l'argile; mais ce schéma demandle à être vérifié soigneusement.

Par exemple : $1^{0}$ une lampe trouvée dans le dépotoir des ateliers de la lluette, dans un ensemble augustéen ou tibérien, avec des gobelets d' $\mathrm{ACO}$ elc., fig. 11 , a ; 20 lig. 15, a et b. détail d'un médaillon signé FELICIS CliRA ; - 30 lig. 12, b, détail d'un érotique raltaché au llaitre d'Hercule (W. A., $\left.n^{0} 8\right) ;-4^{0}$ fig. 3. b. Hercule sur son bùcher; jo fig. 10, a et fig. 8, d (détail), gourde de Vichy. Il faut agrandir assez fortement pour bien faire ressortir les bulles. On remarquera la mème chose sur les reliefs surmoulés chez les Arvernes : ils portent la plupart du temps la trace de deux surmoulages, le plus ancien n'ayant donné que des pelites bulles ; - $6^{\circ} \mathrm{fig.} .8$, a, bet fig. 14 , e, on voit la mème chose sur certains reliefs lyonnais; ; ... $7^{0}$ fig. $14, \mathrm{~g}$, des petiles bulles éparses, et une grosse bulle entre le bras gauche et le flanc d'Anubis ; - $8^{\circ}$ les bulles sont énormes sur le relief d'ANATOR, $\mathrm{n}^{0} 110$, fig. 15, r, d el fig. 15; l'une d'elles. par exemple. tient tout l'avant-bras du jeune homme.

Il est certain, en tout cas, que sous Trajan, le moulage au plâtre était couramment employé car tous les surmoulages trouvés à Lezoux portent des pustules. On peut supposer que le passage aux moules d'argile s'est prorluit dans la vallée du Rhône sous l'influence des techniques arvernes, en pleine activité dans la deuxième moitié du ire siècle.

\section{La mention CERA el l'industrie du bronze.}

Plusieurs reliefs, parmi les plus anciens, ceux de FELIX, APOLLO, APOLIINARIS, LATINVS ${ }^{67}$, portent la mention ('ERA accompagnée d'un nom propre au génitif. On a émis, pour l'expliquer, plusieurs hypothèses. Tout d'abord : que les potiers relevaient des empreintes sur des vases de métal avec de la cire. L'existence des bulles sur les médaillons nous oblige a supposer que l'on tirait du creux ainsi obtenu une empreinte que l'on surmoulait ensuite avec du plâtre. Cela paraît compliquer inutilement le processus : pourquoi ne pas mouler directement un relief avec du plâtre? Nous verrons, un peu plus loin, que cela s'est pratiqué. On a supposé aussi que les potiers modelaient en cire les reliefs qu'ils désiraient mouler ${ }^{68}$. Il faudrait examiner de près la réalisation pratique d'un médaillon en ce matériau. Il semble, par exemple, assez difficile de produire des inscriptions en relief, avec des lettres aussi bien tracées qu'clles le sont habituellement. Celles-ci paraissent plutôt avoir été gravées d'abord en creux. Les aurait-on ajoutées dans un moule en plâtre, alors qu'elles n'existaient pas sur la cire ? Cela paraît étrange, et cette gravure aurait probablement laissé des éclats visibles le long du trait. Ensuite, les négligences du moulage au plâtre, avec ses bulles, et parfois du tirage des épreuves en argile et de leur collage sur le vase, s'accordent mal avec la recherche du détail, du modelé musculaire, qui caractérisent les scènes et les personnages des médaillons. Pourquoi tant de soin, tant de temps passé à parfaire les

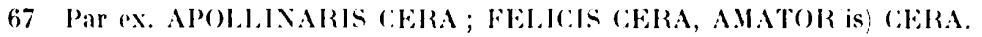

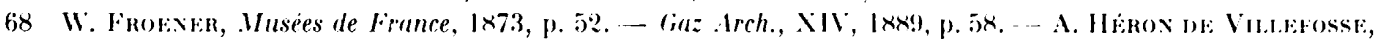
Rev. Ep., V, 1903-6, p. 7.. -.. J. D., II, p. 243. - - W. А., p. 10-11. 

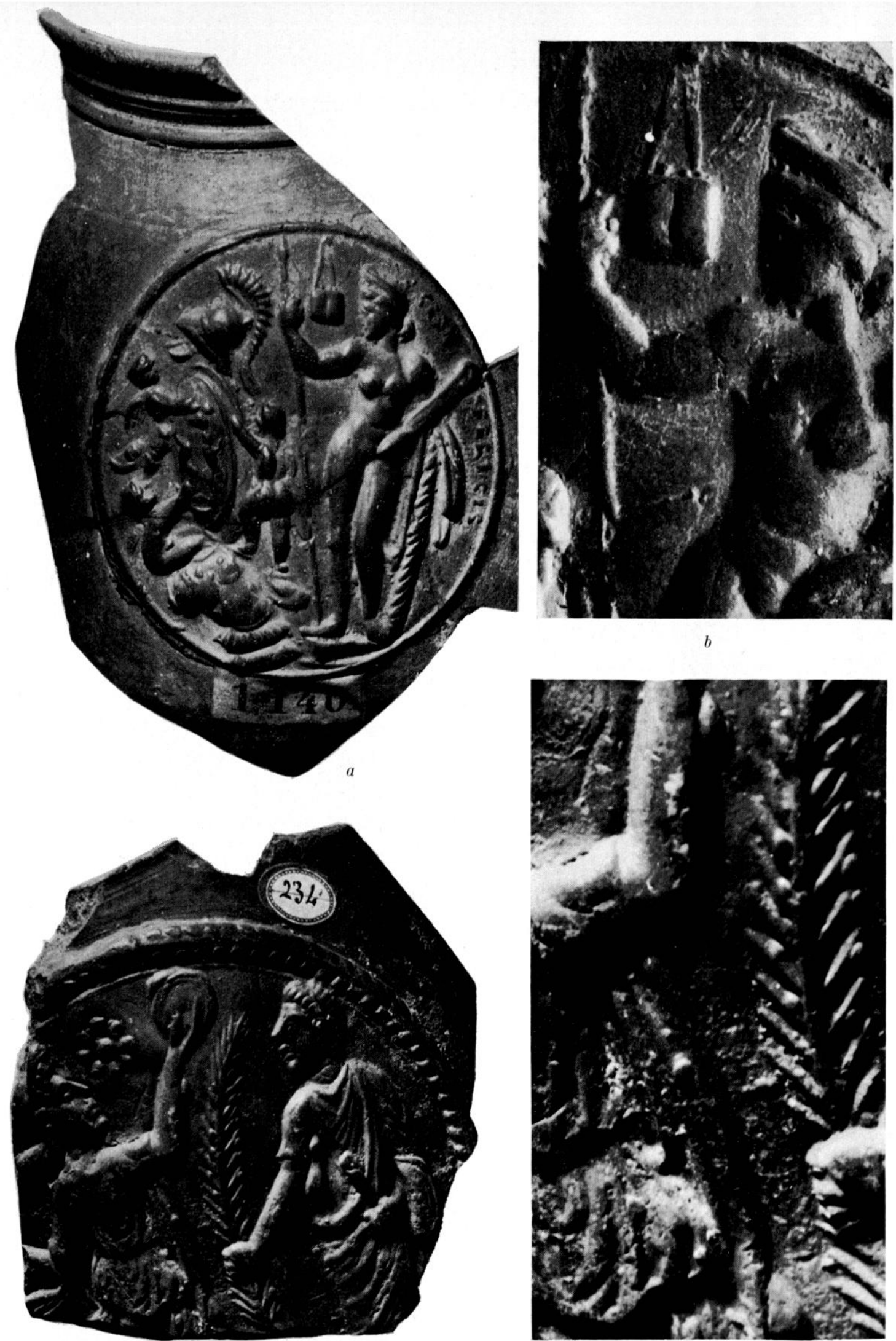

$b$

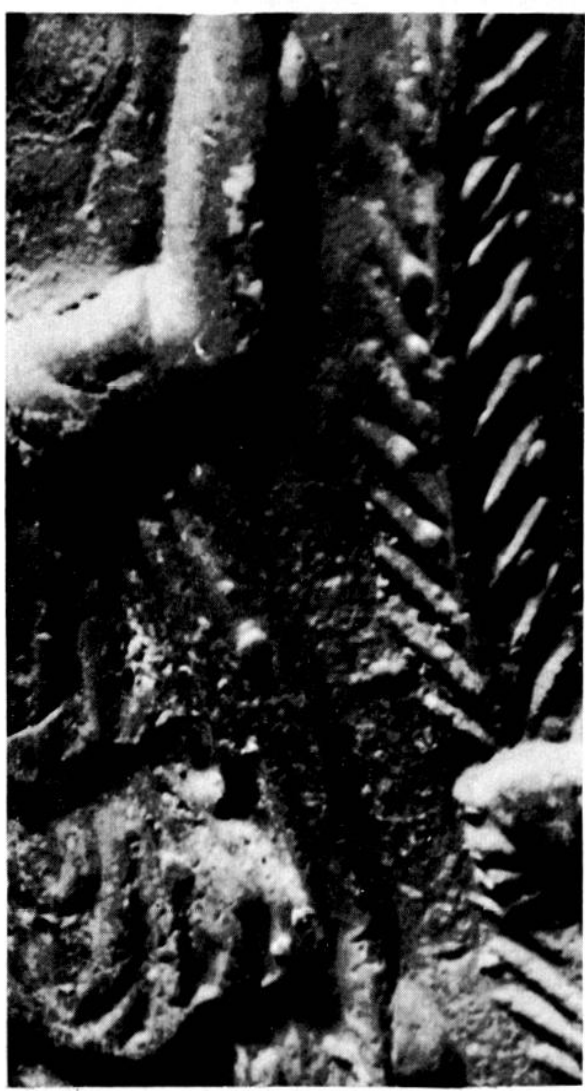

$d$

15 a) Médaillon portant la mention cERA fiELIC:IS W. A., no 13) ; la déesse ne porte pas une massue mais le parazonium. La lance parait avoir été ajoutée a une main que l'on verrait plutót temant un miroir. Des morceaux de la lance sont mal venus et elle n'est pas tres droite; $b$ ) detail agrandi montrant ces irrégularites ainsi que les pustules laissees par te moule en plàtre le document appartenait a la collection Oppermann et se trouve aul Cabinet des lledaillesi ; c) et d) fragment du médaillon W. A., $\mathrm{n}^{\circ} 110$, compléte par une trouvaille en 1961 cf. A. Atwax, lin nouleau médaillon d'applique à la ligende "CALOS C:lPII)O", dans R.A.E., XII, 4, p. 283-286. A gauche, lacteur masculin Cupido, spécialisé dans les röles féminins. La maladresse dans la facon de dessiner les mains est notabje ; celle qui tient la palme devrait ĉtre retournée. Dans l'angle du bras de l'acteur, comme devant le visage du personnage de droile. une petite ligne marque les irrigulariles du coulage du platre. Des bulles, parfois énormes, comme celle qui se trouve a droite, entre l'avant-bras el le tronc du dominus yregis, parsèment la scène. Le médaillon est at tribue au polier A.MATOR. 
prototypes, pour mettre sur le marché des réalisations souvent bàclées ? La disproportion est la même entre les beaux poinçons-matrices de la terre sigillée et les vases mis sur le marché. Lne étude minutieuse a montré que les prototypes n’étaient pas réalisés par les potiers arvernes mais surmoulés sur des motifs de métal ${ }^{69}$. N'existerait-il pas, pour les médaillons aussi, une relation entre plusieurs corps de métiers?

Il serait possible de présenter une autre hypothèse que celles qui ont eté émises pour expliquer cette mention cera. Ln orfèvre consulté, après examen de quelques médaillons de Félix. a conclu plutòt à un travail de graveur sur pierres fines, qu'à celui d'un morleleur de cire. Il lui semble que le type de modelé obtenu est le résultat d'une œuvre exécutée en rreux, et non en bas-relief. Il y a là aussi des recherches à continuer auprès des spécialistes. On sait, a la suite des découvertes récentes de XI. Girange. a Lyon, que des ateliers de bronziers et de potiers étaient installés et fonctionnaient en mème temps sur les bords de la Saòne ${ }^{70}$. Leurs dépotoirs ont eté. en effet, trouvés en couches superposées. Ne peut-on supposer que les artisans de la terre et ceux du métal ont utilisé les mêmes cires, moulées dans des pierres dures gravées en creux, par exemple? Les uns les utilisaient pour des "fontes à cire perdue ${ }^{71} "$, les autres coulaient dessus du plâtre pour en faire leurs moules ${ }^{72}$. La découverte de pierres gravées, non seulement en Égypte mais en divers sites de Gaule (Alésia, Vertault) pourrait faire supposer que ces pierres étaient assez répandues. Ajoutons à cola que certains sujets montrent des reliefs coniques qui paraissent avoir été obtenus par des coups de trépan, outil utilisé parfois dans la gravure des pierres dures. Ainsi se présentent les genoux de plusieurs chevaux (W. A., no 169) (fig. 14, g, h) et certaines lettres, formées de petites boules, réunies par des hastes (ce que m'a fait remarquer V. A. Aurlin).

On pourrait done supposer que, parmi les médaillons les plus anciens, ceux qui portent le mot cera, et d'autres de même facture probablement, ont été moulés sur des cires créées pour des bronziers, peut-être à partir de pierres gravées. Il était facile aux fondeurs d'effacer cette mention avant d'enrober l'objet de sable. L'étude des bronzes des ateliers lyonnais apportera peut-être des documents nouveaux pour cette recherche ${ }^{73}$. Si l'utilisation des

69) Comme cela existait sourent dans les ateliers du Proche-()rient, ainsi que le soulignent M me Mollard-Besque, Courby, plusiemes aulres.

7) I ne ilude est en cours de redaction, dapris les observations de M. Grange, avec les analyses qu'a faites II. I'icon et les examens des reramiques at des stratigraphies que j’ai pu réaliser.

7l "Les moules en pierre nont dialleurs pas éti directement utilisés pour la fonte, sauf celle du plomb, comme lont montre les essais de K.. Prernice : ils auraient été détruits par le métal en fusion. Ils ont servi pour la mise en forme des modiles en cire. Nous avons au louvre le tres rare exemple - car il date sans doute de l'époque hellénistique -.. de deux slatuettes identiques fondues en creux à cire perdue sur le mème nigalif... " J. linarmoxisal:x, Les bronzes yrecs, Paris, 1958, p. 14).

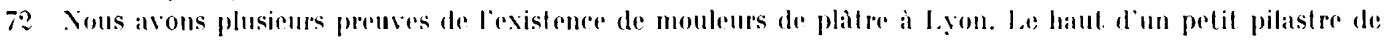

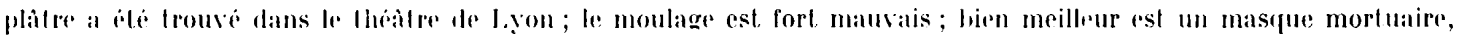

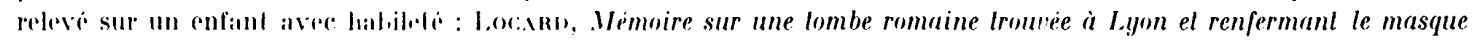

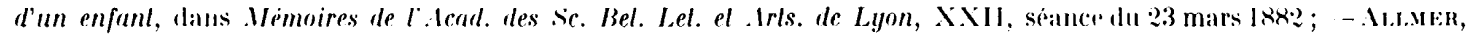

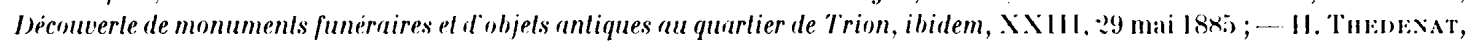

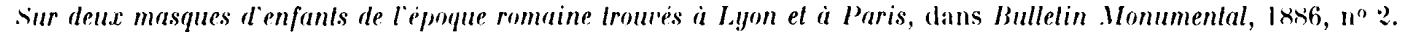

73 Comme dans les aleliers de potiers arvernes, lorsefue l'artisan est coupe de ses prolot ypes de metal, il surmoute:

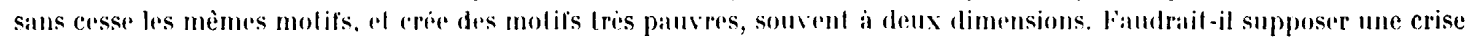

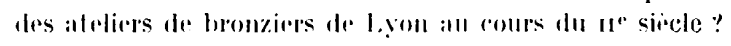


cires de bronziers par les potiers de Lyon et de Vienne n'est actuellement qu'une hypothèse, le surmoulage des reliefs métalliques dans leurs ateliers est attesté. Nous avons trouvé, en effet, à Lezoux, dans le même dépotoir que la gourde signée Surillus, une applique révélatrice. Elle est encrassée de ces perles caractéristiques de leurs productions, ct avait été relevée sur un relief de métal (fig. 14, e).

Nous pouvons remonter cette filière de la façon suivante. Ie dernier surmoulage, peut-être fait chez les Arvernes, a laissé de grosses perles, comme celles que l'on voit au creux et à droite des genoux du personnage debout. Le moulage précédent, probablement le premier, a laissé de toutes petites pustules, assez nombreuses. Elles ont, certes, èté ramenées à une dimension inférieure par l'effet du rétrécissement de l'argile, lors du séchage et de la cuisson de la première applique ; cependant, le plâtre était plus fin ou mieux préparé, ou mieux utilisé car les bulles devaient être petites dès l'origine.

Enfin, l'original métallique est attesté par la ligne des rivets qui entourent l'applique et qui ont été compris dans le décor. On en voit nettement les têtes. Celles qui sont le mieux conservées présentent une couronne de petits points saillants, que je crois décoratifs. Il est vraiscmblable que nous avons affaire à une tôle repoussée car un relief fonclu et épais n'aurait pas demandé d'aussi nombreuses attaches. Quel en était le support? On peut supposer un vase métallique, comme le fait J. Déchelette ${ }^{74}$, mais aussi une ceinture, un vêtement de cuir, un harnais elc. Il est possible aussi que ce ne soient point des têtes de rivets qui entourent la scène mais celles des clous qui la fixaient sur du bois. Nous avons l'exemple de seaux en bois, décorés ainsi de frises en métal repoussé, de coffrets, de fourreaux d'épées etc. Quelques raisons laissent supposer que ces objets sortaient d'ateliers de ciaule.

THÈMI:S ISIAQIES.

Les médlaillons d'applique de la vallée du Rhône présentent, dans leur répertoire, des sujets religieux. On y trouve des dieux gréco-romains, celtiques et orientaux ${ }^{75}$; on est amené a supposer que cette collection d'images nous donne un certain état de la religion populaire, puisque ces vases n'étaient point destinés, semble-t-il, à une clientèle particulière. On voit combien le problème de la chronologie des médaillons est important, par exemple, pour la diffusion des religions orientales en Gaule. J. Déchelette, puis P. Wuilleumier et A. Audin, ont noté que plusieurs médaillons faisaient allusion au culte d'Isis et de cybèle : J. 1)., nos 12 et $13=$ W. A., 202, 335, et 336 : buste d'Isis et de Sérapis ; J. I)., $94=$ W. A. 17 : cortège isiaque ; J. I)., $\mathrm{n}^{0} 51=$ W. A., 157 : Ciybèle assise sur un lion. Wuilleumier et Audin ajoutent une autre représentation de la mème déesse: W. A.. no 30:5. Mais le culte d'Isis semble avoir été plus souvent évoqué encore qu'on ne l'avait pensé. Une étude récente du professeur Alföldi ${ }^{76}$ interprète comme représentation de la déesse des figures où l'on

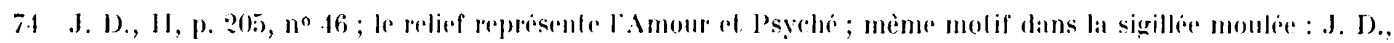
11, p. $40, n^{\circ} 191$.

7) W. A., p. 11 .

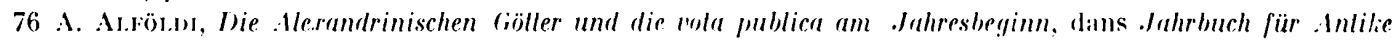
und Chrislenlum, 8:9, 1965-1966, p. $53-87$ at $16 \mathrm{pl}$. 

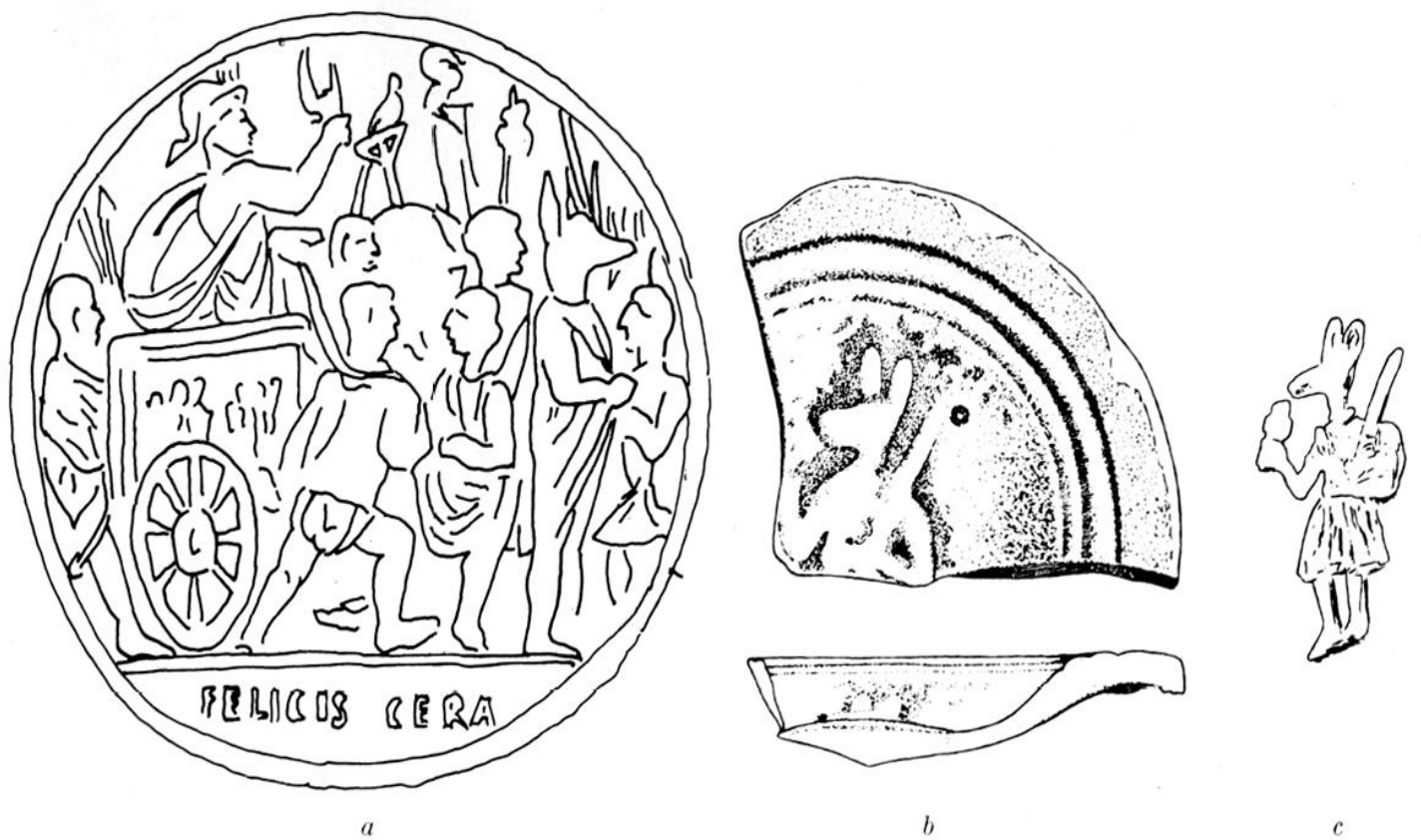

16 Thimes isiaques : a) cortege isiaque : "un prêtre, temant un sistre, se dresse sur un char à deux roues, que trainent des inities, la tête rasée et preciedés par un personnage à tête de chacal, figurant Anubis, et qu'entourent des porleurs

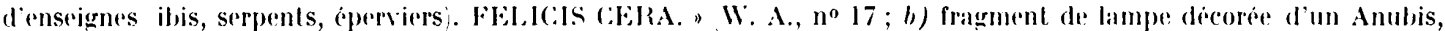
trouve a caerleon. I,e professeur Boon le situe entre les annés 75 el 1.40, el je le remercie vivement de me permettre de donner ici le dessin qu'il a fait de ce document encore inedit. Il me semble que l'on peut attribuer ce tesson alux aleliers lyonnais ; c) Anubis releve dans le répertoire des potiers arvernes, faloricants de lerre sigillée.

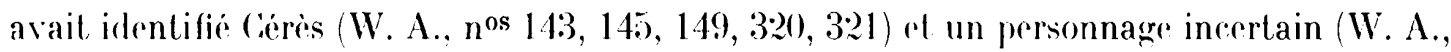
178); le mème auteur voit une parade de fauves isiaque dans les médaillons W. A., 361 et dans quelques autres. Pour ce qui est de la rlate, on plaçait l'apparition de ces témoignages du culte d'Isis à la fin du ${ }_{1}{ }^{\mathrm{e}}$ sièrle. Actuellement, il nous est possible de la reculer avant le ${ }_{11} \mathrm{e}$ siècle, pour plusieurs raisons.

1) Yous avons vu que l'activite de Flill est a placer an ler sierle. Or, il signe une procession isiaque GLRA FEL IGIS (W. A.. 17) (figr. 16. a).

2) Dans l'ensemble clos trouvé à Lezoux et dont j'ai parlé plus haut, avec le supplice de Vlarsyas et d'autres surmoulages lyonnais ont été trouvés les morceaux d'une applique représentant une procession isiaque (fig. 1, e, f). Derrière Anubis, marche un personnage tenant dressée une haute palme. De nombreux personnages le précèdent, drapés, la tête rasée, semble-t-il. II. A. Audin y voil avec certitude le surmoulage d'un médaillon inconnu de FEI.IX. Ce document a été reproduit, sous Trajan, chez les Arvernes.

3) Deux autres reliefs arvernes, identifiés par le professeur Alföldi comme des processions isiaques (J.D., nos 81 a et 81 b. II. p. 217), appartiennent à des vases dont la fabrication est placée au début du ne $^{\mathrm{e}}$ sierle. par la dérouverle, dont je viens de parler, faite à Lezoux et par d'autres trouvailles dans des sites datés. Ce sont vraisemblablement, aussi. par le drapé des personnages, l'ordonnance de la scrine. le slyle général, des surmoulages de FLLIX. 
4) On notera enfin, dans le répertoire de la lerre sigillée moulée arverne, un LXUBSis7 qu'Oswald suppose être de l'époque de Trajan (lig. l(6. r) el qui me semble provenir du répertoire rhodanien. Le professeur Boon, trís aimablement, me signale un fragrment de lampe du Vusée national du pays de (ialles, décoré d'un Anubis un peu plus grand qui pourrait être l'original de celui de la terre sigillée (fig. 16, b). Le bras gauche est un peu plus écarté du corps que sur le type arverne mais cela peut provenir d'une retouche du fabricant de lampes. Lin effel, nous avons aflaire a un exemplaire déjà usagé. La pàte du tesson est blanchàtre, le vernis noir, voire gris-noir et mat, ou presque. Je n'ai pas vu le document mais la finesse de la pate me le ferait volontiers attribuer aux ateliers lyonnais.

Nous pouvons tirer plusieurs conclusions de ces remarques :

a) la région rhorlanienne a vu s’installer les cultes isiaques des le rer sievele. Il est possible que cette extension soit liée à l'appui que lui fournit Caligula ou plutôt, iri, loomitien. Il est possible aussi que la venue d'Asiates hellénophones à lyyon, potiers, verriers, bronziers peut-être, leur ait donné une solide assise populaire ${ }^{78}$;

b) les centres de production céramique arvernes ont fabriqué des reliefs isiaques dès le début du $\mathrm{II}^{\mathrm{e}}$ siècle. On peut se demander si la connaissance de la religion orientale est venue en même temps que le déor : il est difficile de le dire actuellement. On peut cependant souligner que Iezoux et Cilermont ont donné des reliefs mithriaques ${ }^{79}$, que Virhy a fourni des lamelles offertes à Jupiter l)olichénus par CARASSOU NoS ${ }^{80}$ (nom que porte un potier local), que Néris a livré une lampe dédiée a la Maler denm ${ }^{81}$. Il se pourrait donc que l'implantation des religions orientales dans les vici industriels et dans les villes arvernes ait été plus générale quion ne le supposait.

Hugues lertet.

77 Oswat.1, Inder of Figure-lypes on terra sigillala, no 5.19 ; lauleur signale un Anubis qu'il suppose "Masked Mithrasist ", a Itlenweiler sous Hadrien, it Rheinzalbern sous les Antonins, $1^{\circ} 550$; un autre Anubis à Aquincum, a la fin du $\mathrm{u}^{\circ}$ s., $\mathrm{u}^{\circ}$ 5)

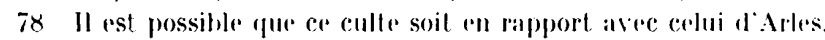

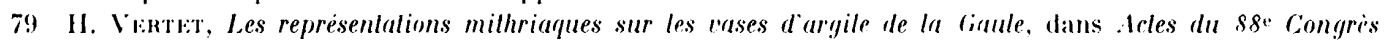
national des Socieless sabantes, C:lermont-Fierrand, 1963, 1. 1.21-129.

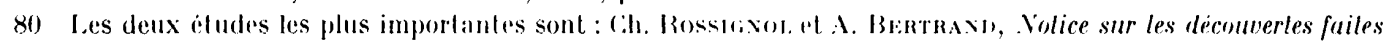

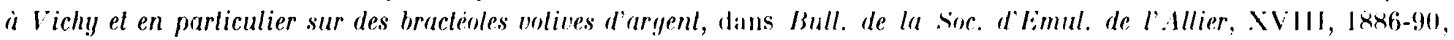

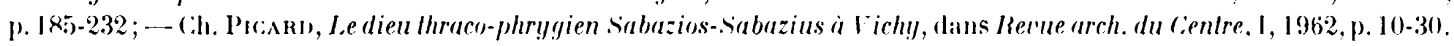

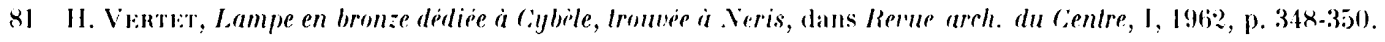




\section{IXNEXE 1}

Deux vases, l'un (/m. zi) décoré de masques, l'antre (/m. 79), sans décor. - - l.es vases à appliques de la vallée du Rhòne ne sont pas ornés seulement de médaillons, mais aussi de reliefs carrés ou rectangulaires (figr. 17), de masques, d'animaux ${ }^{82}$. Il arrive mème que des exemplaires aient été mis sur le marché par les labricants sans aucun décor.

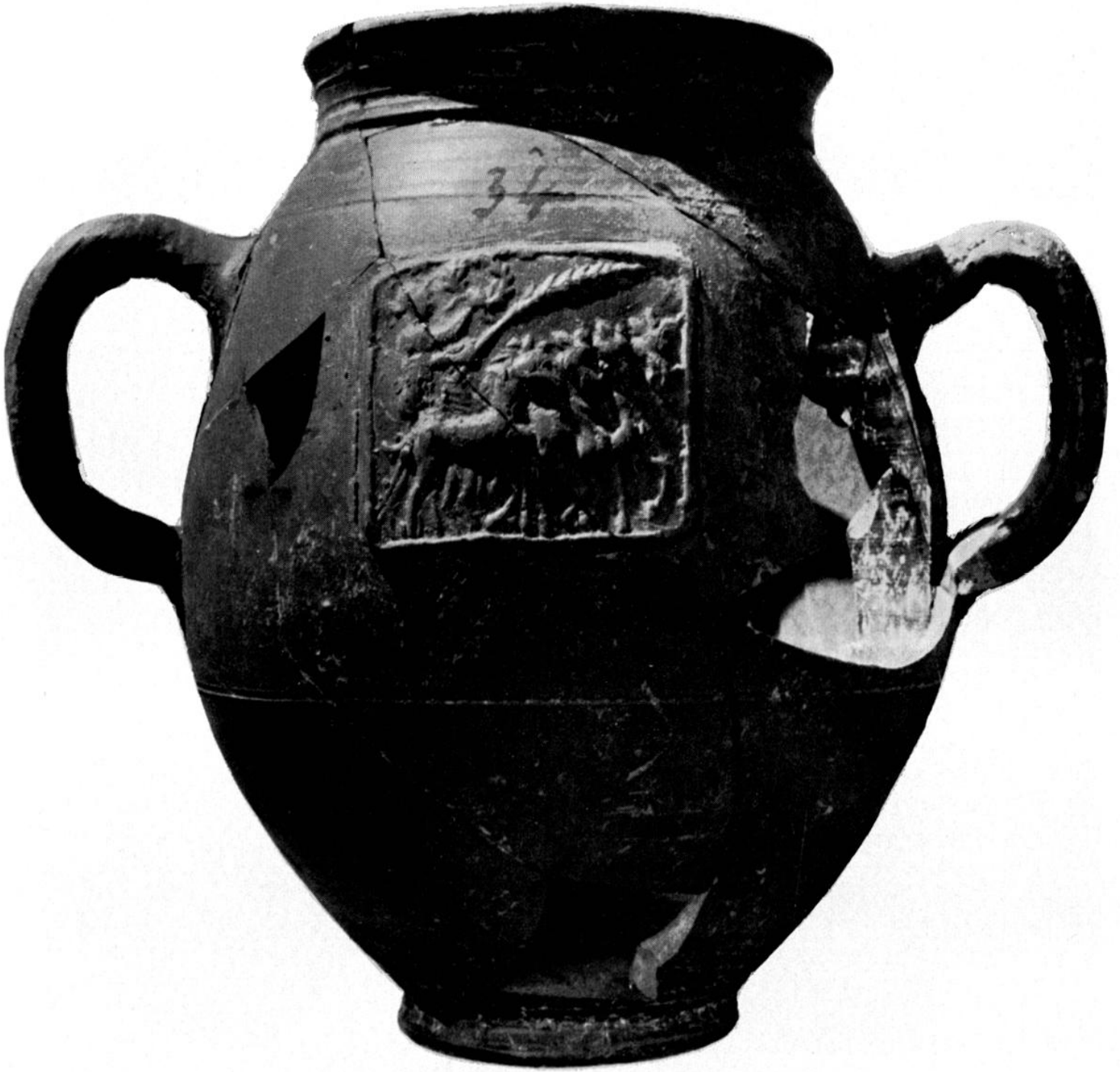

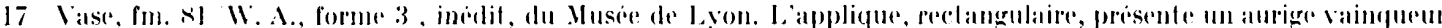

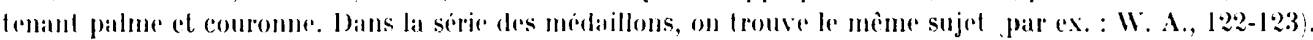

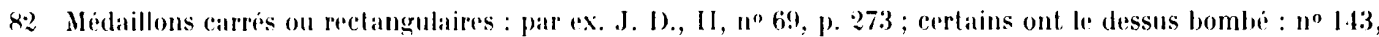
p. 305, ou en forme de toit exemplatere au Vusée de Lyon que me signale aimablement Jacrues Lasfargues . Masque,

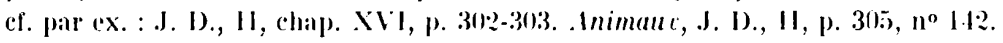



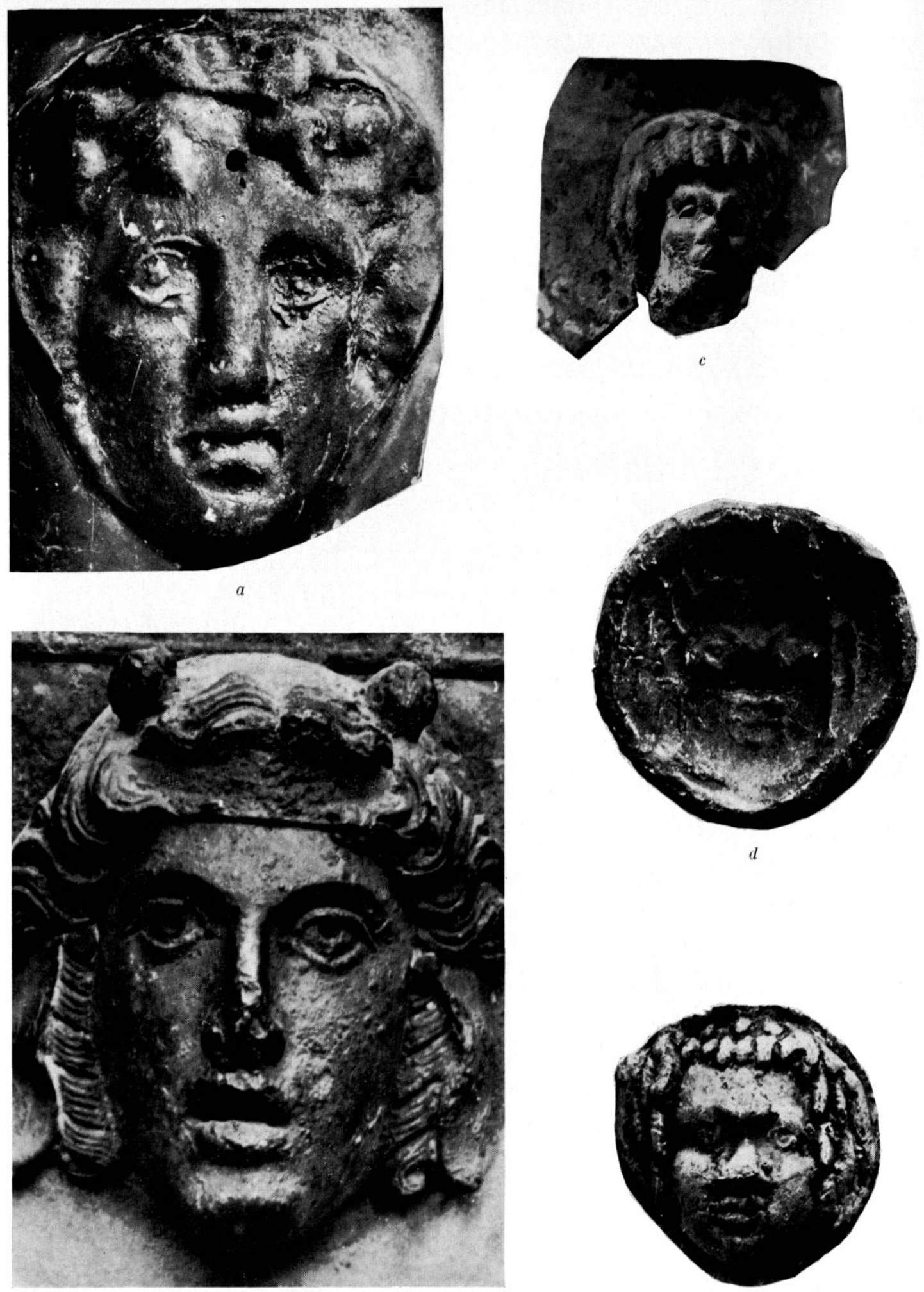

$b$

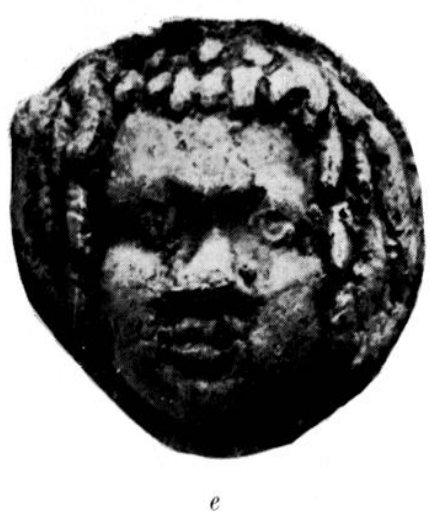

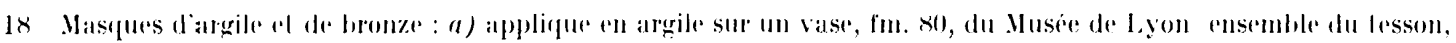
fig. 19, hauteur du visage : $75 \mathrm{~mm}$, large $10 \mathrm{r}: 70 \mathrm{~mm}$. Sur le front, le trou d'event. Des perles provenant du moule en plàtre se voient à la commissure des leveres, autour des paupieres, dans les pupilles. Ia chevelure est couronnée de

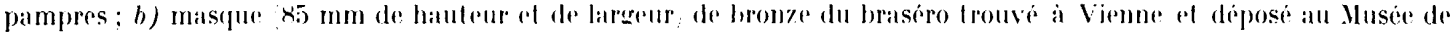
Lyon. Les proportions du visage sont les mèmes quir sur a, de mème que le dessin des paupieres et des levres; c) mascque d' lathiopien qui orne le vase, fm. 77 (fig. : :), b), oppose au masque barbu. On voit combien le lavail du

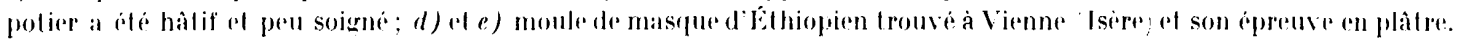

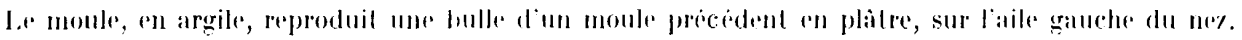


Les reliefs rerlangulaires sont ornés de scènes et d'acclamations analogues ì celles des médaillons. Les masques sont de facture diverse. Les uns, assez grands $(8$ a $12 \mathrm{~cm})$, sont évidés et d'un fort relief (fig. 19), ce qui a obligé le potier à percer un trou d'évent (fig. 18, a) pour éviler le décollage a la cuisson ${ }^{83}$. Ces mèmes masques peuvent aussi être aplatis sur la paroi du vase ${ }^{84}$. I'aulres sont minces et d'asse\% belle facture et représentent des profils alors que les premiers donnent des ligures de face. Une troisième catégorie, moins soignée ${ }^{85}$, porte des têtes de 2 à $3 \mathrm{~cm}$ de hauteur (fig. 18 , c. d, e et fig. 20, b). Actuellement, la faune ne me paraît représentée que par un seul petit sanglier ${ }^{86}$. Pour le moment, rien ne laisse supposer que ces appliques aient été placées sur des vases de formes différentes de celles qui sont ornées de médaillons mais, comme leur répertoire est asse\% réduit, il n'est pas possible d'affirmer absolument que des variantes n'ont pas existé. Le sanglier se trouve à còté de l'érotique (J. I)., $\mathrm{n}^{0} 142=W$. A., $\left.\mathrm{n}^{0} 71\right)$ à $\vdots \mathrm{mm}$ du médaillon environ. Plusieurs masques sont placés sur des formes $\mathrm{n}^{0} 2$ (fig. 19). Heux des petits masques, sur les trois que j'ai relevés, sont collés sur un vase entier trouvé à Vienne. de forme 4 (fig. 20), b).

La fabrication des grands masques est la mème que celle des médaillons. Ils sont parsemés de pustules qui dénolent un surmoulage au plâtre (fig. 18, a). Leur rapport avec des bronzes peut être établi de façon assez précise, grâce à une découverte ancienne faite à Vienne (Isère). Il s'agit d'un braséro rectangulaire, orné, sur ses quatre faces, de trois figures, deux féminines et une masculine. Iasques de métal et masques d'argile ont un relief analogue (fig. 18, a, b). Le style est semblable, le menton nettement marqué, la bouche entr'ouverte, les lèvres sont charnues. les pommettes légèrement marquées, les paupières soulignées d'un relief étroit; le front est à demi caché. L'ovale du visage est asse\% allongé. Les proportions sont les mêmes : si l'on trace une ligne horizontale qui passe par le centre des yeux et si l'on descend une perpendiculaire en son centre, on trouve une distance égale entre les angles extérieurs des paupières et entre la base du nez et le centre du menton. Il n'est pas facile de comparer les chevelures car celles des reliefs d'argile sont, en haut, cachées par une couronne de pampres et, sur le pourtour, aplaties et effacées lors du collage. La pupille est marquée sur les bronzes mais le moulage au plàtre a produil, sur les vases, une bulle qui s'est, facilement accrochée dans ce petil creux. Parfois, le potier a recreusé la pupille d'un coup de gouge.

Les potiers ont-ils surmoulé leurs reliefs sur des masques de bronze trouvés dans le commerce ou sur les cires qui servaient aux coulées? Il n'est pas possible d'affirmer quoi que ce soit actuellement. On pourra peut-ître, cependant, lorsque les analyses en cours seront terminées, dire si ces masques ont été produits par des ateliers locaux et établir ainsi un lien de plus entre les industries du métal et celles de l'argile.

I'ase à pelits masyues de Vienne (fig. 20, b). Il a élé découvert par M. Ruf, conservateur des Ilusées de Vienne (Isère), alors qu'il surveillait les terrassements d'un chantier de H.I..II. Il se trouvait. pris de la surface du sol ; l'engin l'a brisé mais l'inventeur a pu récupérer presque tous les morceaux et les recoller ; il l'a déposé au .lusée local et m'a très aimablement donné l'autorisation de le publier.

La terre et la surface sont rouge brique, avec des variations de nuances; un dépôt calcaire blanchâtre recouvre l'objet en partie et empâte. par endroit, les reliefs. L'épaisseur de la paroi est de $4 \mathrm{~mm}$ au bas de la panse. La hauteur totale du vase est de $140 \mathrm{~mm}$, le diamètre du pied, de $47 \mathrm{~mm}$. le masque barbu a $23 \mathrm{~mm}$, celui de l'Éthiopien (fig. 18, c), $32 \mathrm{~mm}$ de hauteur. Les reliefs sont placés à peu près au centre de la surface délimitée par deux anses. Ils sont collés sans soin, avec une barbotine trop épaisse, trop abondante et le potier a lissé le pourtour des visages, ce qui a écrasé barbes et. (hevelures. Cette mutilation et ce mauvais moulage rendent les comparaisons difficiles. Cependant, on peut rapprocher le masque barbu (fig. 20, b) de cerlaines appliques utilisées par les potiers

83 Pair ex. : J. I)., H, nos 133-135, p. 303.

84 Par ('x. : J. D., II, no 132.

$8 \overline{3}$ J. I., 11, p. 303, n० 134.

86 J. 1)., H, p. 305, n० 142. 


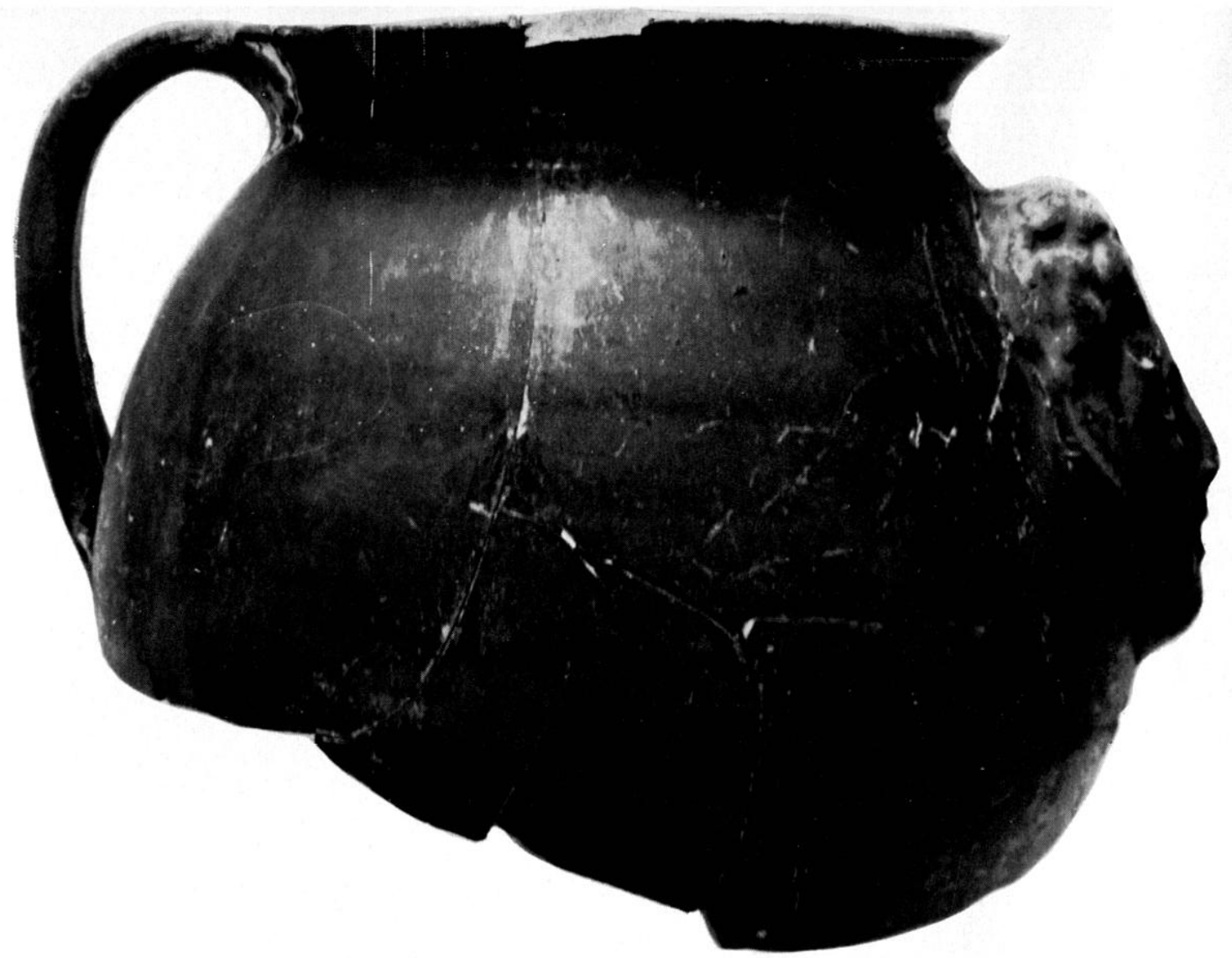

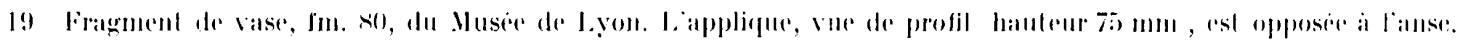

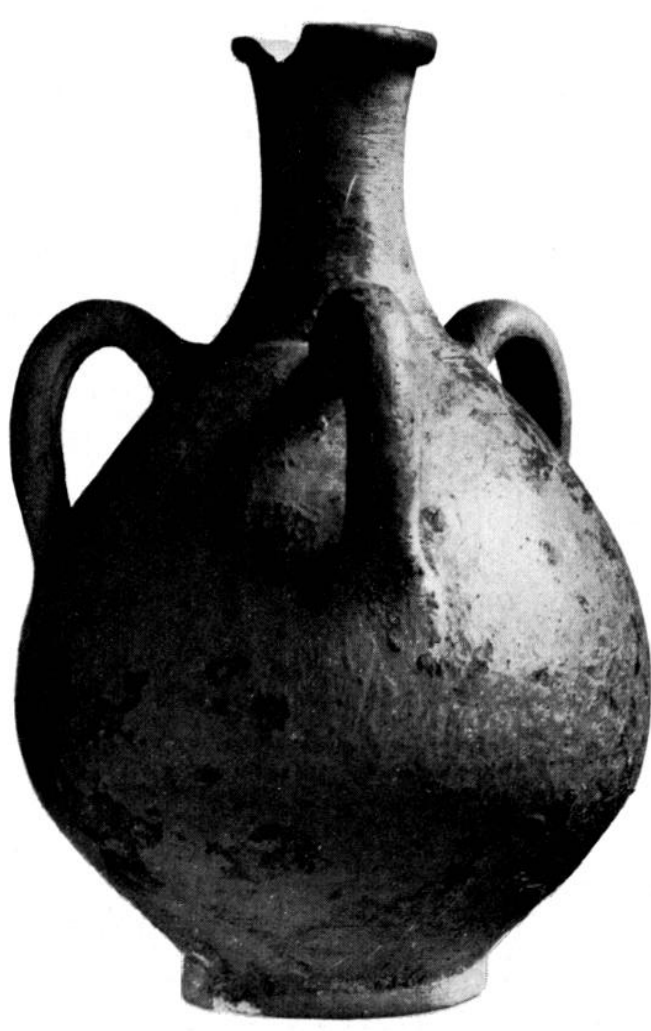

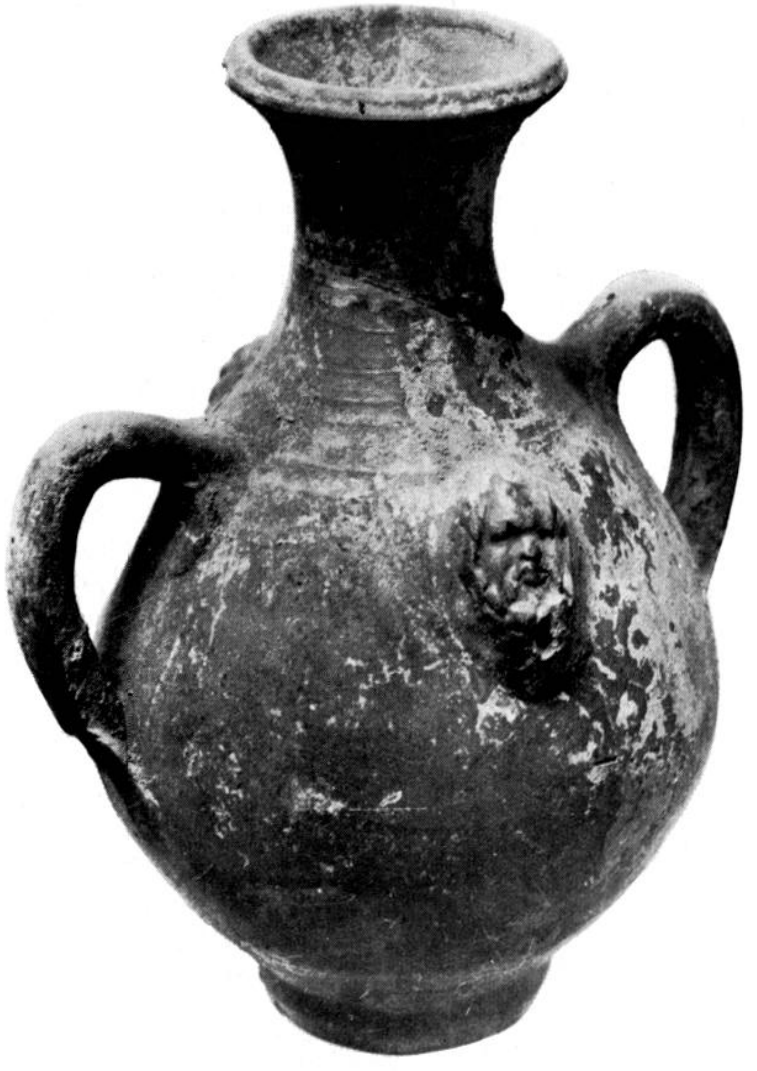

$b$

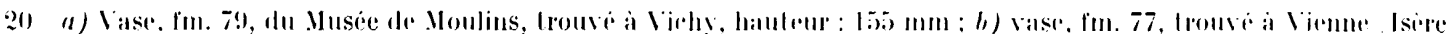

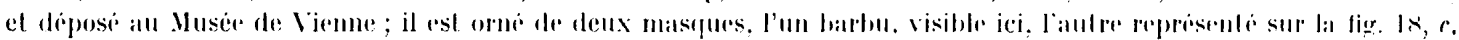


arvernes ${ }^{87}$, ou l'on voit les mimes moustaches tombantes, les memes lives charnues et le front haut rncadré de méches ondulées. Pour ce qui est de l'B́lhiopien. il faut signaler que l'on a découvert a Vienne un petit, moule d'une ligure du mème lype (fig. 18, d, e) : les dimensions sont sensiblement les memes mais les morhes tressées sont plus étroites et plus nombreuses ${ }^{88}$. (On peut aussi trouver facilement des paralleles entre ce type de personnage et les bronzes. les vases plastiques représentant aussi des Éthiopiens étaient fabriqués a Alexandrie et vendus un peu partout ${ }^{89}$. Il est possible aussi que res ateliers de la vallée du Rhòne el du limes aient été influencés par des ouvriers égyptiens.

Cela s'ajoute aux indices qui nous ramenent loujours vers le Proche-(Orient et en particulier vers l'Égypte, dans l'étude des produclions lyonnaises.

Il est probable que les potiers ont orné les vases de dimensions moindres avec de petils masques. Il est possible aussi que nous ayons li une production tardive el que les grands masques aient été. alors. moins employés. Ils semblent en général plus soignés, mais l'absence de contexte archéologique ne permet de faire que des supposilions.

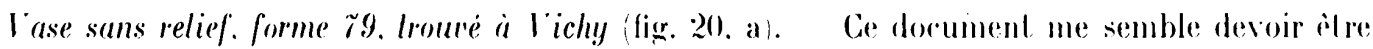
rallaché aux ateliers rhodaniens car ceux de la vallée de l'Allier n'ont pas fabriqué. à ma connaissance, celte forme. C"est le type ) de la série lyonnaise (forme 79) dont on connait plusieurs exemplaires ornés de médaillons ${ }^{90}$.

Il est conservé arluellement au Musée de Noulins ( $n^{\circ}$ 52 20) et est resté inédit. Il a fait partie de la collection Lsmonnot, dont nous avons parlé plus haut. Cette collection réunissait une fort grande quantité d'objets lrouvés dans les fouilles de Vichy ou de sa région et plus loin encore, puisque nous y avons signalé des moules trouvés à Vienne. The partie des objets fut achetée par Bertrand, conservateur du Musée de Moulins el la fiche qui demeure au musée est écrite de sa main. Les provenances données par celui-ci sont moins assurées que celles d'Esmonnot. rependant la provenance "Vichy" est probablement exacte, Vichy ayant donné aussi, au moins. un relief de la vallée du Rhòne. Ies analyses de la pâle préciseront, je l'espère, l'atelier producteur.

I'objet est presque complet; il ne manque qu'un éclat à la lèvre et un autre vers le fond. I a pàte, qui n'est pas trìs dure. est rose, et le vernis, rougre, est détruil en grande partie, comme s'il avait subi un lavage trop brutal. L'épaisseur de la panse est de 3 à $4 \mathrm{~mm}$ vers le fond. la hauteur totale est de $150 \mathrm{~mm}$, le diametre du fond. de 5i) $\mathrm{mm}$. Le vase a trois anses et, entre elles, il n'y a aucune trace de collage, re qui implique que le vase n'a jamais porté d'appliques ${ }^{91}$.

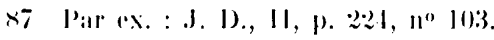

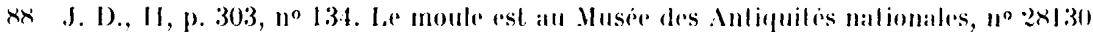

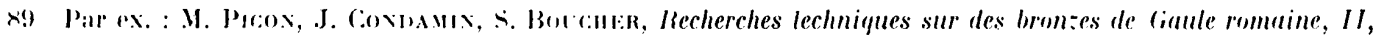
dans liallia, $\mathrm{N} \times \mathrm{V}, 1967$, p. 163, fig. 5, p. 16i), lig. 10.

90) II. A., p. I0, el pl. VIII, 2:35 c.

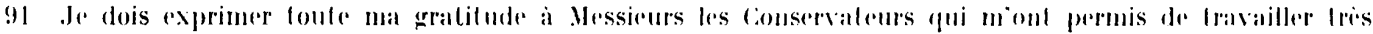
liberalement an Cabinet de Medailles, an Wusere des anliquiles nalionales, an Musere de la Civilisation gallo-romaine a Lyon, aux Musées de Vienne et de Moulins a a lous les savants qui mont aide de leurs remarques, en particulier

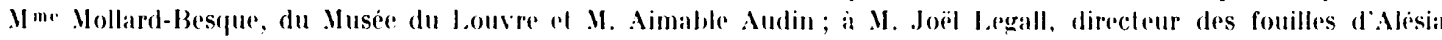

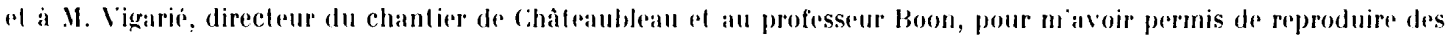
documents de leurs fouilles. I. ('s photographies sont de H. Vertel, sauf fig. 2 a, que je dois a lobligeance de M. Legall.

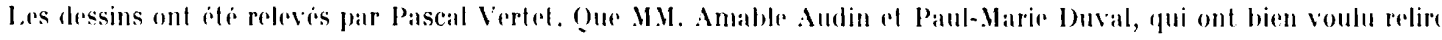
co lexte, verullent tomver ici l'expression de mes remereiements. 
Axxext II

Concordance des numerotations I)echelette et Wuilleumier-Audin

Déch. W. A. potier Déch. W. A. potier Déch. W. A. potier

\begin{tabular}{|c|c|c|c|c|c|c|c|}
\hline 6 & I & 37 & 372 & XXI & 70 & 145 & XI \\
\hline 105 & IX & 38 & 230 & XVII & 71 & 146 & XI \\
\hline 105 & IX & 39 & 164 & XI & 72 & 147 & XI \\
\hline 31 & II & 40 & 166 & X I & 73 & 324 & XX \\
\hline 277 & XX & 41 & 189 & XI & 74 & 152 & XI \\
\hline 29 & II & 42 & 171 & XI & 75 & 174 & XI \\
\hline 4 & I & 43 & 189 & XII & 76 & 208 & XIX \\
\hline 172 & XI & 44 & 187 & XII & 77 & 15 & I \\
\hline 141 & XI & 45 & 190 & XII & 78 & 27 & II \\
\hline 142 & XI & 46 & & & 79 & 33 & II \\
\hline 342 & $\mathrm{XX}$ & 47 & 162 & XI & 80 & 16 & I \\
\hline 202 & XIII & 48 & 209 & XIX & 81 & 28 & II \\
\hline 335 & XX & 49 & 93 & VIII & 82 & 28 & II \\
\hline 306 & XX & 50 & 24 & II & 83 & 54 & II \\
\hline 184 & XII & 51 & 316 & XX & 84 & 85 & VII \\
\hline 325 & XX & 52 & 2 & I & 85 & 81 & VII \\
\hline 154 & XI & 53 & 46 & II & 86 & 82 & VII \\
\hline 155 & XI & 54 & 303 & XX & 87 & 41 & II \\
\hline 176 & XI & 55 & 161 & XI & 88 & 58 & IV \\
\hline 293 & XX & 56 & 369 & XXI & 89 & & \\
\hline 14 & I & 57 & 5 & I & 90 & & \\
\hline 106 & IX & 58 & 21 & II & 91 & 198 & XIII \\
\hline 175 & XI & 59 & 368 & XXI & 92 & 199 & XIII \\
\hline 13 & I & 60 & 3 & I & 93 & 200 & XIII \\
\hline 186 & XII & 61 & 157 & XI & 94 & 17 & I \\
\hline 370 & XXI & 62 & 9 & I & 95 & 45 & II \\
\hline 40 & II & 63 & 96 & IX & 96 & 158 & XI \\
\hline 74 & $\mathrm{~V}$ & 64 & tête de Cybèle & & 97 & & \\
\hline 68 & $\mathrm{~V}$ & $65 \mathrm{a}$ & 97 & IX & 98 & 44 & II \\
\hline 68 & $\mathrm{~V}$ & $65 \mathrm{~b}$ & 103 & IX & 99 & 108 & IX \\
\hline 375 & XXI & $65 c$ & 100 & IX & 100 & 302 & XX \\
\hline 376 & XXI & $65 \mathrm{~d}$ & 99 & IX & 101 & 1 & I \\
\hline 64 & $\mathrm{~V}$ & 66 & 102 & IX & 102 & 110 & IX \\
\hline 371 & XXI & 67 & 322 & XX & 103 & 57 & III \\
\hline 73 & $\mathrm{~V}$ & 68 & 323 & XX & 104 & 292 & XX \\
\hline 373 & XXI & 69 & 273 & XIX & 105 & 36 & II \\
\hline
\end{tabular}


Déch. W. A. potier Déch. W.A. potier Déch. W. A. potier

$\begin{array}{lrrrrrrrr}106 \mathrm{a} & 38 & \text { II } & 126 & 71 & \text { V } & 146 & & \\ 106 \mathrm{~b} & 39 & \text { II } & 127 & 20 & \text { I } & 147 & 356 & \text { XX } \\ 107 & 113 & \text { IX } & 128 & 252 & \text { XVIII } & 148 & 42 & \text { II } \\ 108 & 114 & \text { IX } & 129 & 298 & \text { XX } & 149 & 51 & \text { II } \\ 109 & 194 & \text { XII } & 130 & 267 & \text { XVIII } & 150 & 318 & \text { XX } \\ 110 & 291 & \text { XX } & 131 & \text { masque } & & 151 & 179 & \text { XI } \\ 111 & 194 & \text { XII } & 132 & \text { masque } & & 152 & 127 & \text { IX } \\ 112 & 290 & \text { XX } & 133 & \text { masque } & & 153 & 280 & \text { XX } \\ 113 & 291 & \text { XX } & 134 & \text { masque } & & 154 & 68 & \text { V } \\ 114 & 116 & \text { IX } & 135 & \text { masque } & & 155 & 64 & \text { V } \\ 115 & 213 & \text { XV } & 136 & \text { masque } & & 156 & 26 & \text { I } \\ 116 & 195 & \text { XII } & 137 & 26 & \text { IX } & 157 & 11 & \text { I } \\ 117 & 19 & \text { I } & 138 & 12 & \text { I } & 158 & 79 & \text { VII } \\ 118 & 112 & \text { IX } & 139 & 194 & \text { XII } & 159 & 84 & \text { VII } \\ 119 & 111 & \text { IX } & 140 & 272 & \text { XIX } & 160 & 315 & \text { XX } \\ 120 & 205 & \text { XIV } & 141 & 104 & \text { IX } & 161 & 48 & \text { II } \\ 121 & 206 & \text { XIV } & 142 & 71 & \text { V } & 162 & 269 & \text { XIX } \\ 122 & 255 & \text { XVIII } & 143 & 276 & \text { XIX } & 163 & 18 & \text { I } \\ 123 & 122 & \text { IX } & 144 & 380 & \text { XXI } & 164 & 113 & \text { IX } \\ 124 & 124 & \text { IX } & 145 & 10 & \text { I } & 165 & 211 & \text { XV } \\ 125 & 254 & \text { XVIII } & & & & & \end{array}$

